Article

\title{
Improving Ventilation Efficiency for a Highly Energy Efficient Indoor Swimming Pool Using CFD Simulations
}

\author{
Gabriel Rojas ${ }^{1, *(\mathbb{C} \text { and Jessica Grove-Smith }}{ }^{2}$ \\ 1 Unit for Energy Efficient Buildings, University of Innsbruck, Innsbruck 6020, Austria \\ 2 Passive House Institute, 64283 Darmstadt, Germany; jessica.grovesmith@passiv.de \\ * Correspondence: gabriel.rojas-kopeinig@uibk.ac.at
}

Received: 26 September 2018; Accepted: 9 November 2018; Published: 15 November 2018

\begin{abstract}
The operation of a typical indoor swimming pool is very energy intensive. Previous studies have shown that high quality thermal building envelopes, i.e., with high levels of insulation and airtightness, make it possible to rethink conventional ventilation concepts. Due to the reduced condensation risk in and on envelopes of high thermal quality, ventilation design can be optimized for indoor air quality rather than for averting condensation on the facade. This work investigates different air distribution concepts for an existing swimming pool via computational fluid dynamics (CFD) simulations to evaluate their ventilation efficiency. To reduce modelling and computational resources, the velocity and turbulence fields produced by the swirl-diffusers are determined in a set of separate CFD simulations and incorporated into the swimming pool models. The results show that the ventilation efficiency in the examined swimming pool could potentially be improved with various alternative air distribution concepts, therefore improving the indoor air quality. Although the results seem plausible and compare well with the limited measurement data of air humidity, a more formal experimental validation is still needed before generalizing recommendations.
\end{abstract}

Keywords: swimming pool; ventilation efficiency; air exchange efficiency; contaminant removal efficiency; CFD; Passive House

\section{Introduction}

Swimming is a popular leisure and sports activity, and on that account many municipalities provide swimming facilities for public use. However, the operation of a typical indoor swimming pool is very energy and water-intensive and therefore also costly. Municipalities are increasingly faced with the question of how they can continue to afford to provide such subsidized facilities, and reducing the operating costs of indoor swimming pools is a decisive factor. One promising approach is to significantly increase the level of energy efficiency, i.e., reduce the energy needs for heating the space and the water, as well as the electricity needs for ventilation, for operating the water treatment systems and for any further facilities. In addition to the lowered operating costs, the benefits of increased energy efficiency in public swimming pools are planning security for the municipality's household due to the reduced impact of rising energy prices, the high quality and longevity of the building envelope, and a high level of user comfort, as well as making a contribution to climate change mitigation and facilitating a transition to sustainable energy supply structures.

It is well established that energy demand in conventional indoor swimming pools is dominated by pool water and space heating and that the majority of the pool water heat is lost via evaporation [1-3]. Reported total annual energy use from existing swimming pools range around $4000 \mathrm{kWh}$ per square meter water surface $\left(\mathrm{kWh} / \mathrm{m}_{\mathrm{WS}}^{2} \mathrm{a}\right)$ or, when reported in terms of usable area, 
around $600 \mathrm{kWh} / \mathrm{m}_{\mathrm{UA}}^{2}$ a [4,5]. Potential energy saving potentials have been identified and investigated with a focus on improving the efficiency of heating, ventilation, and air conditioning (HVAC) systems $[3,6-8]$.

The achievable energy savings by applying a high quality thermal envelope, as typical for Passive House construction, have been investigated and confirmed through the detailed analysis of monitoring results of two pilot projects [2,9-12]. Passive House is an internationally established performance-based energy standard for highly energy efficient buildings [13-15]. The concept focusses on optimizing a building's design and identifying appropriate components to significantly reduce the energy needs for heating and for cooling, as well as for the overall primary energy needs to operate all facilities within the building. Applied to swimming pools, the quality of a Passive House building envelope-with high levels of insulation and airtightness-make it possible (amongst other things) to rethink conventional ventilation concepts, thus rendering opportunities for energy savings and ventilation efficiency. Figure 1 provides an overview of the main correlations.

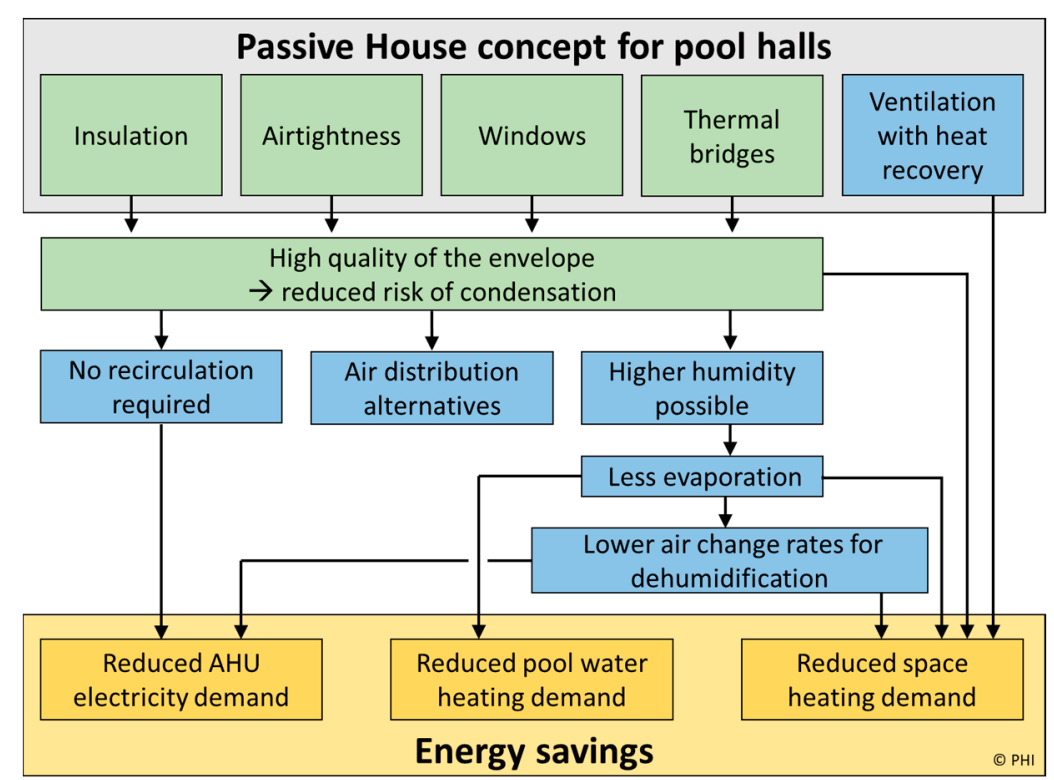

Figure 1. Schematic showing how the high thermal quality of the Passive House envelope provides opportunities for additional energy savings by optimizing the ventilation concept for pool halls. Source: Adapted from [16], Passive House Institute.

The ventilation of indoor swimming pools serves two main purposes: ensuring good air quality (removing any contaminants in the air, especially by-products of the chemical water treatment) and dehumidifying the air to the desired humidity level. Traditionally, the heated supply air in swimming pools is directed onto the exterior facades in order to prevent condensation on the cold surfaces. The volume flow of fresh outdoor air which is required for dehumidification is supplemented with recirculation air in order to keep the supply air flow rate at a constant level. Figure 2 shows typical proportions of outdoor air and recirculation air over the course of a year.

Due to the high surface temperatures of a well-insulated Passive House envelope with curtain walling of a high thermal quality, it is no longer necessary to blow high flow rates of warm air onto the façade. As part of the energy savings concept for Passive House swimming pools, it is thus recommended to operate the ventilation in pool halls without recirculation air, which entails a significant reduction of the electricity demand. Furthermore, air inlets should be positioned for an optimized air distribution in light of comfort, energy impact and contaminant removal. Various disinfection by-products are formed when chlorine products react with compounds introduced by humans $[17,18]$. In particular, trichloramine $\left(\mathrm{NCl}_{3}\right)$ and trihalomethans (THMs) can be found abundantly in gaseous form in swimming pool air $[18,19]$. Respiratory symptoms and eye irritation 
have been associated with high levels of trichloramine, e.g., [20-23]. Identifying suitable air distribution strategies is, however, not a trivial task due to the highly variable flow rates, as well as the constant evaporation and contaminant transfer at the surface of the pool water. This question therefore merits further investigation, as presented in this paper. By simulating different air distribution strategies for an example pool hall, their respective effectiveness can be compared.

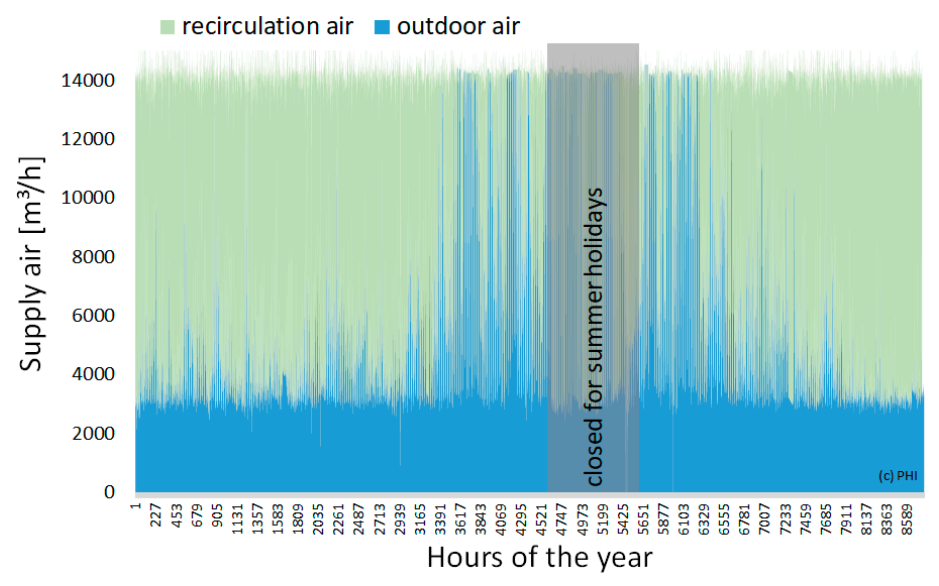

Figure 2. Exemplary hourly mean values of outdoor air and recirculation air volume flows, as measured in a pool hall in Germany. Due to higher outdoor humidity, the required fresh air rate for dehumidification is higher during summer months. The required peaks during summer are decisive for sizing the ventilation unit responsible for outdoor air exchange. Source: Passive House Institute.

The following paper reports the methods and results of a study using computational fluid dynamics (CFD) in order to evaluate different ventilation concepts in terms of their ventilation efficiency. CFD methods have been widely used to investigate air, heat, moisture and/or pollutant transport in indoor swimming pools or large spaces. For example, airflow, thermal comfort and/or indoor air quality has been evaluated for swimming pools $[24,25]$ or an ice rink arena [26]. The experimental validation of CFD models of large indoor spaces has been documented on various occasions [27-30]. CFD methods have also been used to calculate the evaporation rate in indoor swimming pools [31,32].

Simulating large spaces with air diffusers is challenging since the required spatial discretization needed to accurately simulate the airflow around the diffuser drastically increases the total number of elements for the simulation domain. Various approaches, including the "box method" used herein, have been described and assessed in literature [33,34]. The CFD model presented herein is based on an existing swimming pool facility [9] and results cannot necessarily be generalized. Nevertheless, possible ventilation approaches for highly energy efficient swimming pools are examined with the intention to provide orienting guidelines for mechanical systems designers. Additionally, this work documents a CFD methodology for simulating large indoor swimming pool halls while considering complex diffuser geometry.

The ventilation concept is a crucial aspect for high energy efficiency in indoor swimming pools. Achieving overall high energy efficiency in swimming pools, however, entails many more topics. The details are beyond the scope of this paper and can be found in the full research publication [12].

\section{Materials and Methods}

\subsection{Geometry and Ventilation of the Examined Indoor Swimming Pool}

The investigated swimming pool is part of larger facility built and owned by the municipal utility of the German city of Bamberg. This facility was designed for 1100 visitors per day and has a gross floor area of around 13,500 $\mathrm{m}^{2}$ accommodating various pools and areas including a sport pool, two instructional pools, a leisure/family pool area, a water slide area, an exterior pool area 
as well as a sauna and wellness area [9]. The outer walls are made of concrete with an exterior insulation layer of $30 \mathrm{~cm}$ mineral wool. They have a total wall thickness of $55 \mathrm{~cm}$ with an U-value of $0.135 \mathrm{~W} /\left(\mathrm{m}^{2} \mathrm{~K}\right)$. The wooden roof construction is insulated with $28 \mathrm{~cm}$ of expanded or extruded polystyrene foam (EPS/XPS) and an additional $8 \mathrm{~cm}$ thick layer of mineral wool resulting in an U-value of $0.097 \mathrm{~W} /\left(\mathrm{m}^{2} \mathrm{~K}\right)$.

The presented study investigated the sport pool hall only. It is roughly $57 \mathrm{~m}$ long, $32 \mathrm{~m}$ wide and $9 \mathrm{~m}$ high. The basin is roughly $50 \mathrm{~m}$ by $20 \mathrm{~m}$ (see Figure 3). The geometry was simplified and symmetries were considered to reduce the required computer resources for CFD simulation as much as possible. In this context, the floorplan of the pool area was reduced to a rectangular form; i.e., the curved exterior walls were not considered.

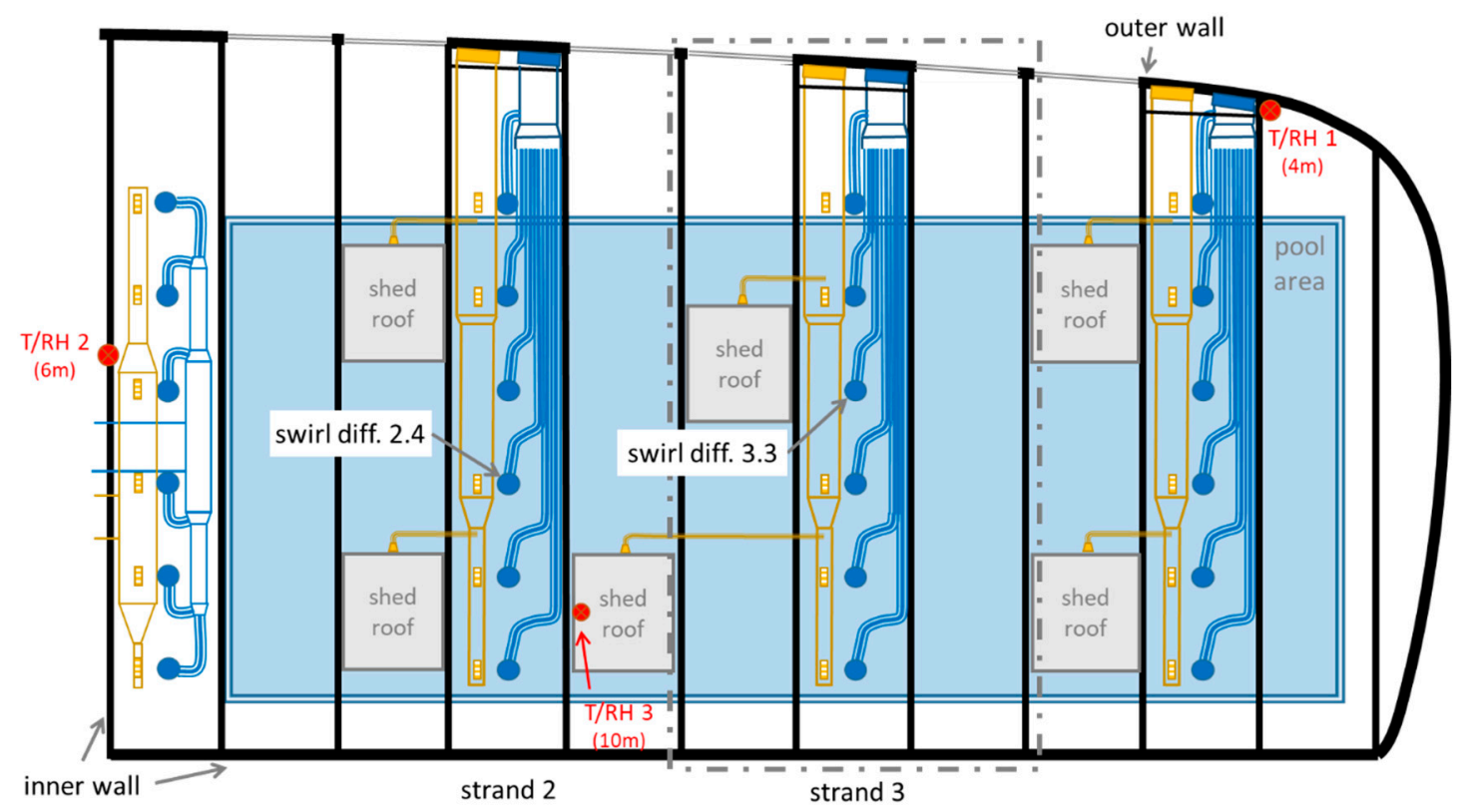

Figure 3. Relevant section of the floor plan of the investigated swimming pool hall. It also shows the ventilation ducting (supply air in blue, extract air in yellow), which has four strands. The supply air is introduced via 24 (6 per strand) swirl diffusers mounted in the ceiling. The ceiling is divided into 11 vertical strips by wooden roof trusses. The locations of the temperature and humidity sensors are also shown.

The hall of the sport pool and the adjacent water slide area are ventilated by two identical ventilation units with a total capacity of $64,000 \mathrm{~m}^{3} / \mathrm{h}$ (ThermoCond R 37, Menerga, Mülheim an der Ruhr, Germany). The supply air is introduced via 24 ceiling swirl diffusers (SD) of type VDL-A-H-D 630 (Trox, Neukirchen-Vluyn, Germany) [35]. Most of the exhaust air is extracted via the shadow gaps of the suspended ceiling. Only a minimal proportion (about $1800 \mathrm{~m}^{3} / \mathrm{h}$ of $64,000 \mathrm{~m}^{3} / \mathrm{h}$ ) is extracted from the six shed roof areas. These areas were neglected in the CFD simulations. The 24 swirl diffusers are on four ventilation strands, as shown in Figure 3. The ceiling is divided into 11 (and half) "strips" by wooden roof trusses, with the ventilation ducts mounted behind the suspended ceiling in every third ceiling strip. According to information from the planning office, the shadow gaps of the suspended ceiling are approx. $5 \mathrm{~cm}$ wide (see Figure 4).

In general, the simplified hall geometry can be divided into four periodic sections. However, depending on the set point of the supply air flow, certain swirl diffusers are deactivated via valves. This control strategy ensures that the flow through each diffuser only ranges roughly between $1500-2100 \mathrm{~m}^{3} / \mathrm{h}$. In this case, the periodicity is no longer given. For simulations with all diffusers being active, i.e., maximum or close to maximum flow, only one section with three of the mentioned ceiling strips was simulated, namely the section of ventilation strand 3 (see Figure 3). This section was also chosen as the simulation domain when alternative ventilation concepts with linear periodicity 
were considered. For simulations with minimal supply air volume flow and only one active diffuser per strand, two sections (strands 2 and 3 in Figure 3) were simulated. This is because, at minimum operation, the only active diffusers are at different locations (either at position No. 3 or No. 4; see Figure 3). According to planning documents, 50,400 $\mathrm{m}^{3} / \mathrm{h}$, i.e., $12,600 \mathrm{~m}^{3} / \mathrm{h}$ per strand, are introduced into the hall during nominal operation. This is almost $80 \%$ of the total volume flow of the two ventilation units $\left(2 \times 32,000 \mathrm{~m}^{3} / \mathrm{h}\right)$. The rest of the mechanical ventilation with heat recovery (MVHR) units' capacity is for the water slide area. It was assumed that this ratio does not change under partial load operation. Thus, the specified minimum air flow into the pool hall is $7560 \mathrm{~m}^{3} / \mathrm{h}$. This is confirmed by reported measurements, where total flows (including slide area) of $\sim 9000 \mathrm{~m}^{3} / \mathrm{h}$ were recorded [9]. This corresponds to an air flow of $1890 \mathrm{~m}^{3} / \mathrm{h}$ per diffuser. In order to reduce modeling and simulation efforts, a "near" maximum variant with $45,360 \mathrm{~m}^{3} / \mathrm{h}$ supply air volume flow $\left(24 \times 1890 \mathrm{~m}^{3} / \mathrm{h}\right)$ was modelled instead of the maximum $50,400 \mathrm{~m}^{3} / \mathrm{h}$.

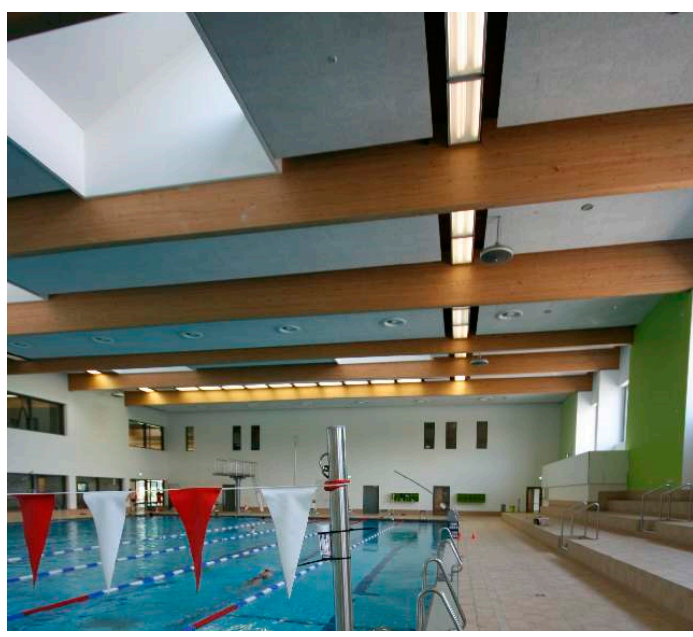

(a)

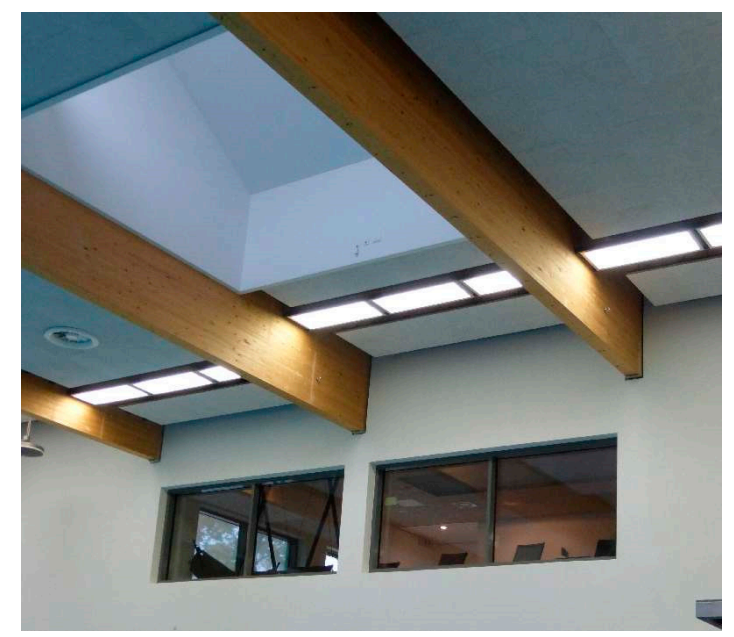

(b)

Figure 4. Photographs of the hall accommodating the sport pool: (a) general view; (b) view of the wooden trusses, one shed roof area, and the suspended ceiling including one swirl diffuser. In the same "strip", the air is extracted through the gap between suspended ceiling and wooden trusses. Source: Passive House Institute.

\subsection{Boundary Conditions for Reference Case and Variants}

The boundary conditions for the CFD simulations were based on reported measurement [9] and are summarized in Table 1 . Within that monitoring study, temperature and humidity were continuously measured with a sensor accuracy of $+/-0,1 \mathrm{~K}$ and $+/-3 \%$ relative humidity (RH, Hygrasgard RFTF, S + S Regeltechnik, Nürnberg, Germany) in three locations in the hall and in the supply and extract air of the ventilation air handling units. The sensors were calibrated before installation. The measurements of a representative two-week period in winter are shown in Figure 5. The volume flow of the air handling units was also recorded.

Using an empirical formula from VDI 2089 guideline [36] to calculate the evaporation from the pool surface, the resulting stationary air humidity was calculated in an simple iterative mass balance calculation. Assuming a supply air humidity of $9 \mathrm{~g} / \mathrm{kg}$ and a water transfer coefficient $\beta$ of $28 \mathrm{~m} / \mathrm{h}$, as recommended in VDI 2089, a supply air flow close to maximum capacity would result in an $R H$ of around 55\%; see variant " $\mathrm{A}$ " Table 1 . Note that a $R H<60 \%$ was required. Measurements show that these high-flow conditions, representing the summer case, were hardly reached [9]. The measured winter conditions (supply air flow, ambient and indoor humidity, see Figure 5) can be reproduced assuming a water transfer coefficient $\beta$ of $10 \mathrm{~m} / \mathrm{h}$. With an ambient air humidity of $4 \mathrm{~g} / \mathrm{kg}$, this represents the low flow rate case; see variant " $\mathrm{B}$ " in Table 1 . Note that these calculated extract air humidity values were also used to check CFD results and convergence. 
Table 1. Overview of the simulated variants and their corresponding boundary conditions including temperatures $(T)$, absolute humidity $(X)$, volume flow $\left(\dot{V}_{S A}\right)$, water transfer coefficient $(\beta)$, resulting evaporation rate $\left(\dot{m}_{\mathrm{H} 2 \mathrm{O}}\right)$ and relative humidity $(R H)$ with the following abbreviations: supply air (SA), extract air (EA), outer wall (OW) and inner wall (IW).

\begin{tabular}{|c|c|c|c|c|c|c|c|c|c|c|}
\hline ID & Variant Description & $\begin{array}{l}T_{S A} \\
{\left[{ }^{\circ} \mathrm{C}\right]}\end{array}$ & $\begin{array}{l}T_{\text {Room }} \\
{\left[{ }^{\circ} \mathrm{C}\right]}\end{array}$ & $\begin{array}{c}X_{S A} \\
{[\mathrm{~kg} / \mathrm{kg}]}\end{array}$ & $\begin{array}{c}\dot{V}_{S A} \\
{\left[\mathrm{~m}^{3} / \mathrm{h}\right]}\end{array}$ & $\begin{array}{c}N r . \\
{[-]}\end{array}$ & $\begin{array}{c}\beta \\
{[\mathrm{m} / \mathrm{h}]}\end{array}$ & $\begin{array}{l}\dot{m}_{\mathrm{H} 2 \mathrm{O}} \\
{[\mathrm{kg} / \mathrm{h}]}\end{array}$ & $\begin{array}{c}X_{E A} \\
{[\mathrm{~g} / \mathrm{kg}]}\end{array}$ & $\begin{array}{c}R H_{E A} \\
{[-]}\end{array}$ \\
\hline \multicolumn{11}{|c|}{ As-Is variants } \\
\hline- & Max. flow, VDI Guideline & 32.5 & 30 & 0.009 & 50,400 & 6 & 28 & 305.9 & 14.3 & 0.55 \\
\hline $\mathbf{A}$ & High flow rate, $\beta=28 \mathrm{~m} / \mathrm{h}$ & 30.2 & 30 & 0.009 & 45,360 & 6 & 28 & 293.8 & 14.6 & 0.56 \\
\hline B & Low flow rate, $\beta=10 \mathrm{~m} / \mathrm{h}$ & 40.0 & 30 & 0.004 & 7560 & 1 & 10 & 97.6 & 15.2 & 0.59 \\
\hline \multicolumn{11}{|c|}{ Alternative variants } \\
\hline B1 & Vertically discharging & 40.0 & 30 & 0.004 & 7560 & 1 & 10 & 97.6 & 15.2 & 0.59 \\
\hline B2 & EA @ OW & 40.0 & 30 & 0.004 & 7560 & 1 & 10 & 97.6 & 15.2 & 0.59 \\
\hline B3 & EA @ OW + vert. discharging & 40.0 & 30 & 0.004 & 7560 & 1 & 10 & 97.6 & 15.2 & 0.59 \\
\hline B4 & EA @ pool edge & 40.0 & 30 & 0.004 & 7560 & 1 & 10 & 97.6 & 15.2 & 0.59 \\
\hline B7 & EA @ pool edge + vert. dis. & 40.0 & 30 & 0.004 & 7560 & 1 & 10 & 97.6 & 15.2 & 0.59 \\
\hline B5 & SA @ OW + EA @ IW (linear) & 40.0 & 30 & 0.004 & 7560 & $\mathrm{n} / \mathrm{a}$ & 10 & 97.6 & 15.2 & 0.59 \\
\hline B6 & SA @ OW + EA @ IW $(1 \times)$ & 40.0 & 30 & 0.004 & 7560 & $\mathrm{n} / \mathrm{a}$ & 10 & 97.6 & 15.2 & 0.59 \\
\hline A5 & SA@ OW + EA @ IW (linear) & 30.3 & 30 & 0.009 & 50,400 & $\mathrm{n} / \mathrm{a}$ & 28 & 305.9 & 14.3 & 0.55 \\
\hline A6 & SA@ OW + EA @ IW $(1 \times)$ & 30.3 & 30 & 0.009 & 50,400 & $\mathrm{n} / \mathrm{a}$ & 28 & 305.9 & 14.3 & 0.55 \\
\hline
\end{tabular}

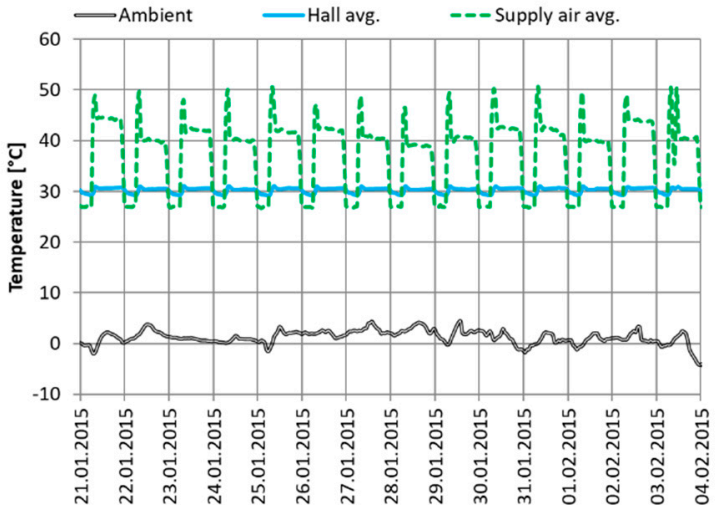

(a)

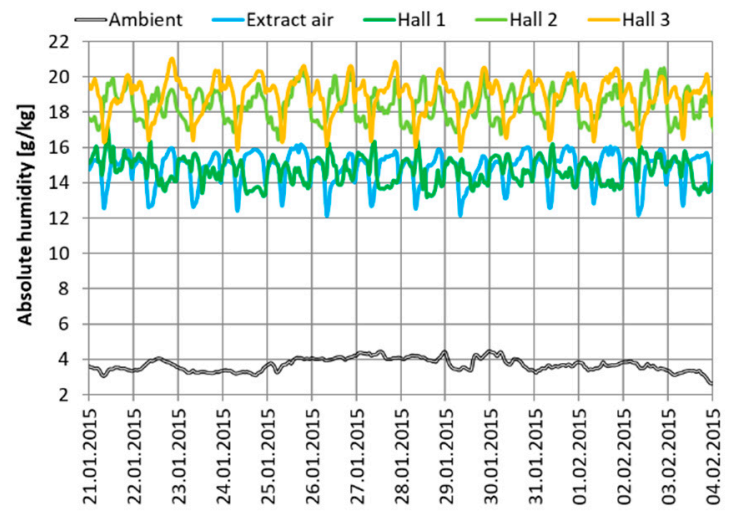

(b)

Figure 5. Measured temperature (a) and humidity (b) in the investigated swimming pool hall [9] for a representative period in winter. The location of the sensors is shown in Figure 3.

The as-is cases represent the ventilation concept as implemented in the presented swimming pool. Alternative ventilation strategies, i.e., ways of supplying and extracting the air, were explored. Based on the two operating states (A and B), nine variants were modeled and simulated. All variants, together with the corresponding boundary conditions, are summarized in Table 1.

Since the as-is configuration of the supply air diffusers and extract air outlets seemingly has some short circuit flow between them, variant "B1" was modelled to test if the ventilation efficiency could be improved with vertically discharging swirl diffusers. Simulations of variants "B2" and "B3" were performed to determine ventilation performance with extract air outlets close to the floor. According to a HVAC professional specialized in swimming pool design, supplying air at ceiling level and extracting air at floor level is advantageous in terms of air exchange while reducing evaporation rates [37]. Therefore, the extract air outlets were modelled in the outer wall where the ventilation ducts are routed in the as-is configuration. This would imply a relatively easy retrofit.

Based on simpler 2D CFD simulations, performed during a preliminary study [38], a higher ventilation efficiency was expected when air was extracted around the pool edges. Therefore, variants "B4" and "B7" were included in this study. Configurations "B5" and "B6" (and "A5/A6") have 
the intention to simplify and reduce ducting by also supplying air at floor level. In this way, no duct routing to the ceiling would be required. For these variants, the supply air outlet was modelled as a simple upward-discharging slit along the outer wall. The extract air opening was either modelled as a continuous linear opening (thin slit) along the inner wall or as single rectangular opening on the inner wall (one per simulation domain).

\subsection{CFD Model of the Swimming Hall}

The CFD simulations were performed with the software ANSYS Fluent 17.2 (Canonsburg, PA, USA). It numerically solves a set of coupled partial differential equations, i.e., the Navier-Stokes equations. They can be written as

$$
\begin{gathered}
\frac{\partial \rho}{\partial t}+\nabla \cdot(\rho \vec{v})=S_{m} \\
\frac{\partial}{\partial t}(\rho \vec{v})+\nabla \cdot(\rho \vec{v} \vec{v})=-\nabla \mathrm{p}+\nabla \cdot(\dot{\tau})+\vec{F} \\
\frac{\partial}{\partial t}(\rho E)+\nabla \cdot(\vec{v}(\rho E+p))=\nabla \cdot\left(k_{e f f} \nabla T-\sum_{j} h_{j} \vec{J}_{j}+(\overline{\bar{\tau}} \cdot \vec{v})\right)+S_{h}
\end{gathered}
$$

Respectively, they express the conservation of mass, momentum and energy, with $\rho, p, \vec{v}$ and $E$ representing density, pressure, velocity and energy. $S_{m}, S_{h}$ and are mass and energy source terms and $\vec{F}$ represents external body forces, such as the gravitational force. Viscous forces are considered by the stress tensor $\overline{\bar{\tau}}$, which for an incompressible and isotropic Newtonian fluid can be expressed as

$$
\overline{\bar{\tau}}_{i j}=\mu\left(\frac{\partial v_{i}}{\partial x_{j}}+\frac{\partial v_{j}}{\partial x_{i}}\right)
$$

with $\mu$ being the dynamic viscosity. In the energy equation, the term $k_{e f f} \nabla T$ represents the heat conduction given by Fourier's law, with $k_{\text {eff }}$ being the effective conductivity, which includes turbulent thermal conductivity given by the respective turbulence model. The terms $h_{j} \vec{J}_{j}$ and $(\overline{\bar{\tau} \cdot \vec{v}})$ account for energy transfer due to species diffusion and viscous dissipation, respectively, with $\vec{J}_{j}$ being the diffusion flux and $h_{j}$ the sensible enthalpy of species $j$. Note that in the simulations presented herein, air was treated as incompressible, a valid assumption as long as the characteristic air velocity is much smaller than the speed of sound. Under this assumption, the conservation equations simplify accordingly (see e.g., [39]).

For CFD simulations, the volume of interest needs to be discretized into small volumes and one needs to find a good compromise between available computer resources, required accuracy and modelling efforts. A particular challenge in this case was the large volume of the simulated pool section in combination with swirl diffusers. Although many areas of the volume exhibit low air flow velocities, e.g., the center of the hall, the areas in and around the diffusers require very fine discretization.

For this reason, the method often referred to as a "box method" was chosen [33,34]. Within a detailed model, the outflow from the supply air diffuser was simulated. From the simulation results, the velocity field and that of the turbulence variables $(k$ and $\varepsilon$ ) are extracted and applied as a boundary condition on the corresponding surfaces in the pool hall model. For this purpose, a hemisphere with a radius of $0.5 \mathrm{~m}$ was modelled at the position of each swirl diffuser and the velocity and turbulence profile was imposed. Since a substantial backflow into the hemisphere area (induction) develops, especially in the horizontally discharging case, the correct energy and mass balance over this hemisphere had to be ensured. This means that, depending on the temperature, tracer concentration or water content of the air flowing into the hemisphere, the temperature, tracer concentration and water content of the outflowing air has to be adjusted in each simulation step. To accomplish this, 
so-called "user-defined functions" were programmed and integrated into the ANSYS Fluent simulation model [40].

Furthermore, the simulation of natural convection with small driving forces can be challenging, as the computation may poorly converge. Therefore, efforts were made to model and subdivide the simulation domain in a way that would allow the effective meshing of the volume. Figures 6 and 7 show how the geometry of the simulation domain was defined, including the periodic boundary planes.

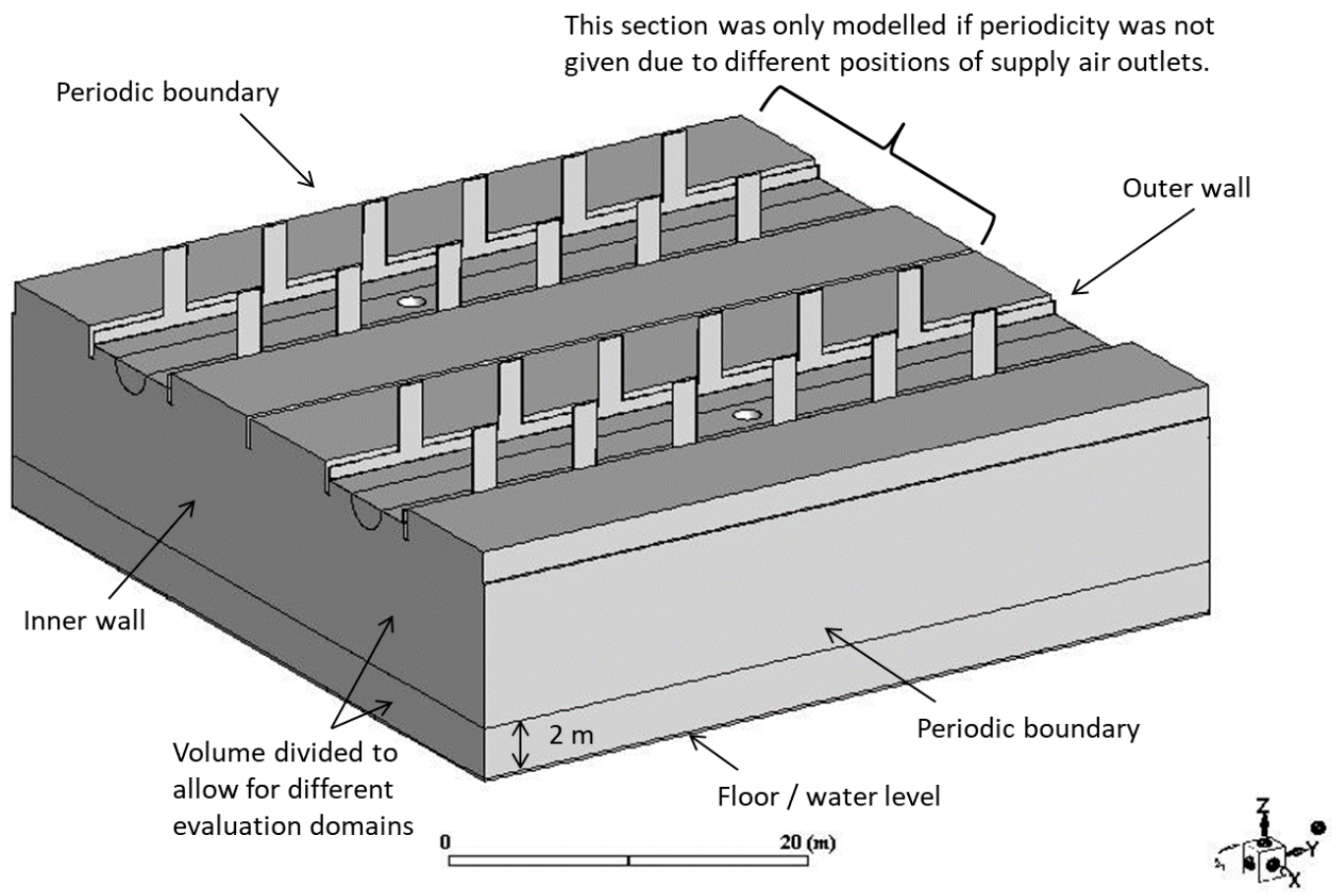

Figure 6. Three-dimensional view of the geometric hall model used for the computational fluid dynamics (CFD) simulations.

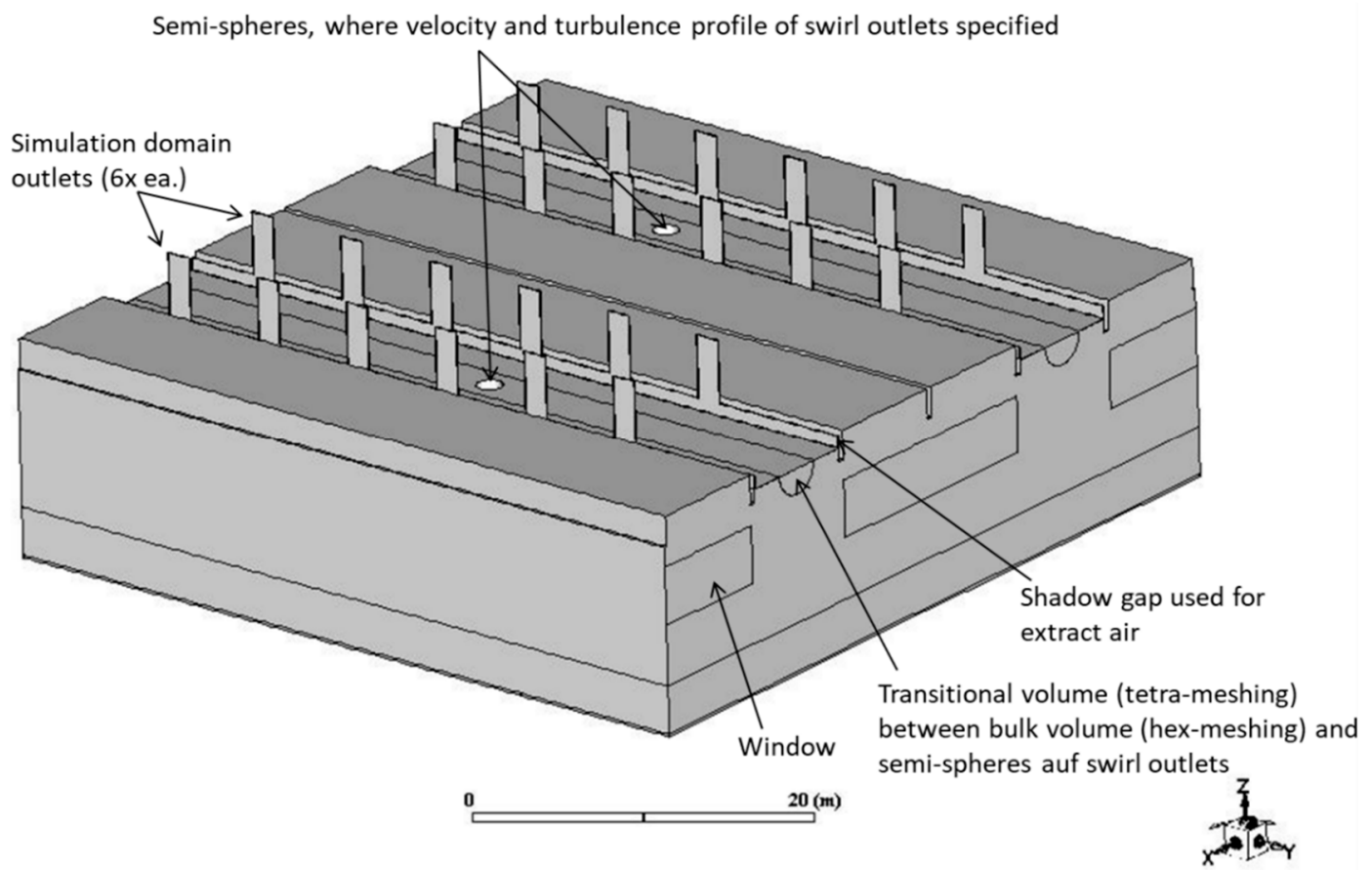

Figure 7. Three-dimensional view towards the outer wall of the geometric hall model. 


\subsubsection{Meshing}

To reduce computational resources, a hex mesh (in prisms) was applied wherever possible. In order to be able to impose individual boundary conditions on certain surface sections (for example, water surface, windows, etc.), the volume was split into several sections (see Figure 8).

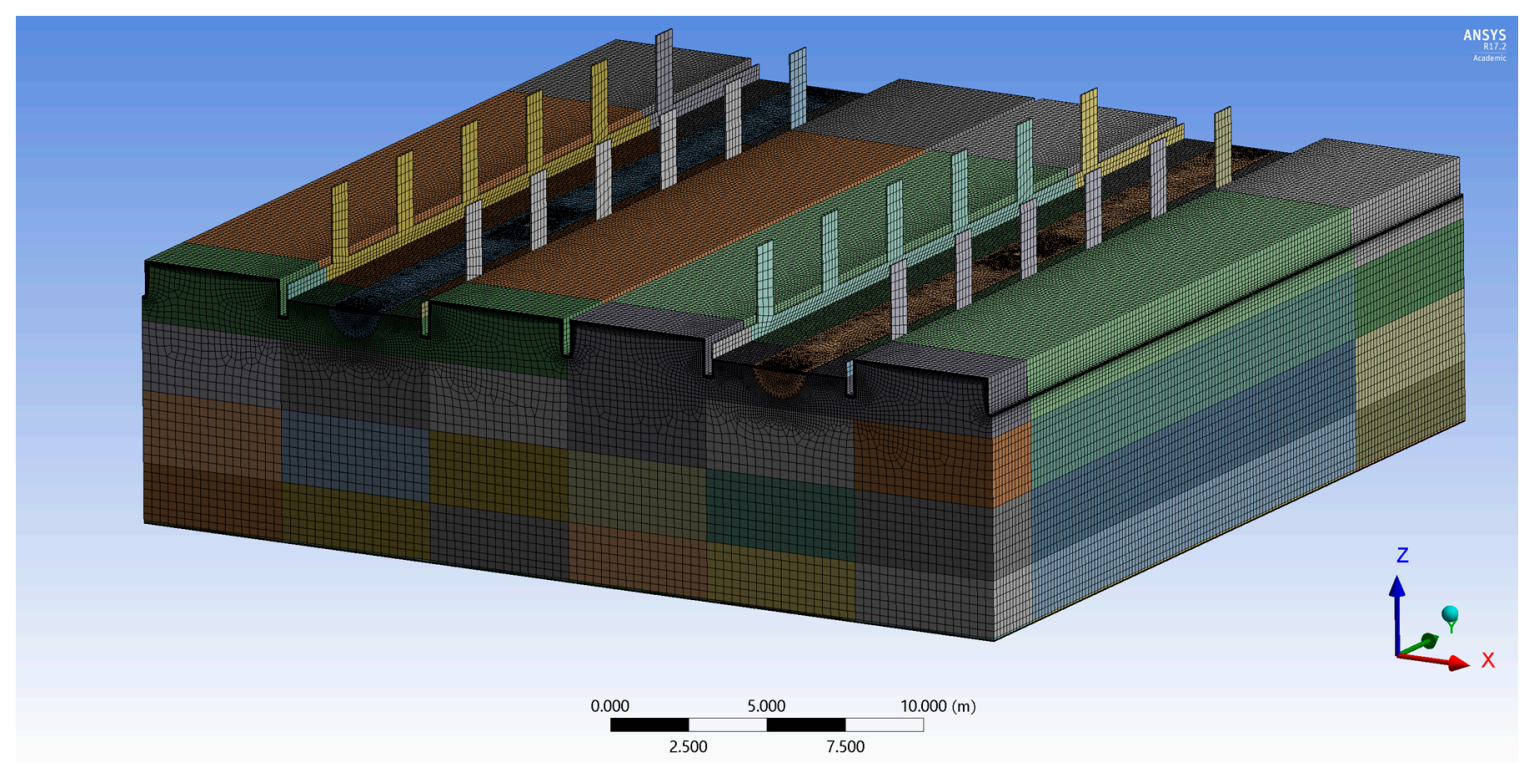

Figure 8. Three-dimensional visualization of the mesh for the model of variant "B".

Since hex meshing could not be applied in the volume around the diffuser hemispheres, a half-cylinder was defined as a transitional volume with tetrahedral meshing (see Figure 9).

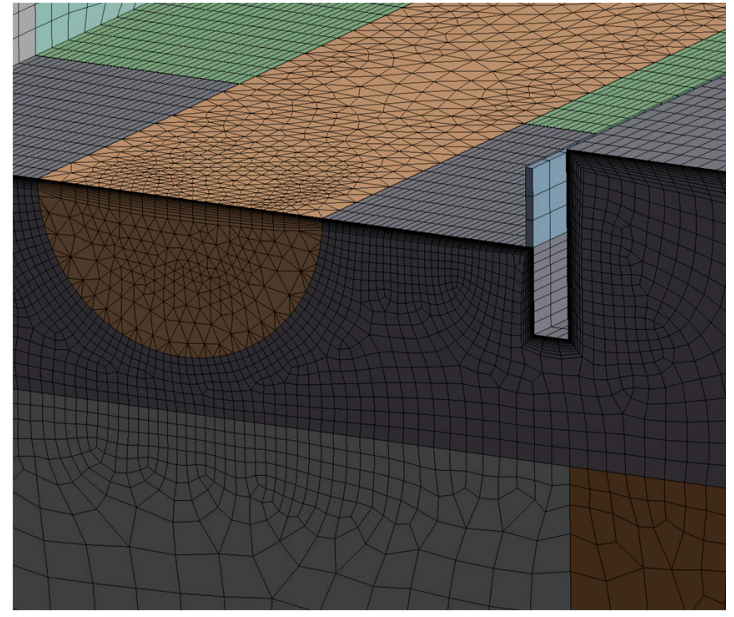

(a)

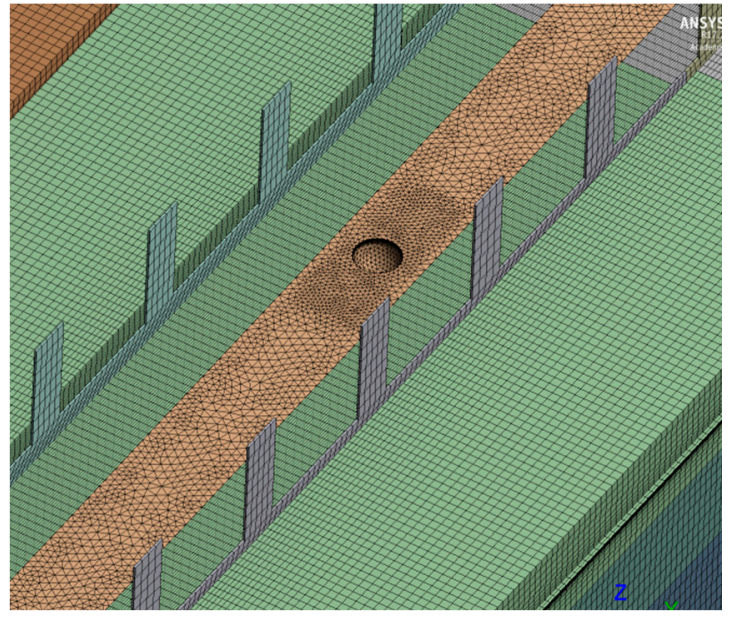

(b)

Figure 9. Detailed views of the mesh of variant "B": (a) around the extract air outlets (shadow gap);

(b) around the supply air inlet (hemisphere).

Different mesh refinement settings were tested for the reference model (variant " $\mathrm{A}$ ") and the results in terms of air exchange efficiency $(A C E)$ were compared. Amongst others, the default element size was varied between 20 and $30 \mathrm{~cm}$, with edge sizing between 2 and $5 \mathrm{~cm}$ and different levels of near-wall element refinements resulting in roughly 2 to 6 million elements. If convergence was achieved, ACE was within $4 \%$ of the result presented in Table 2 . Finally, a mesh with good convergence properties was selected. It was generated with a default element size of $30 \mathrm{~cm}$, with refinements 
in volumes where higher velocities or gradients were expected. For example, the element size was limited to a maximum of $5 \mathrm{~cm}$ on the hemisphere surfaces and on the ceiling surfaces of the center strip, where the flow is dominated by the swirl diffusers (see Figure 9). Furthermore, the volume in the topmost ceiling area was restricted to a maximum element size of $10 \mathrm{~cm}$. For all relevant surfaces, in particular in the middle ceiling area, the near-wall discretization was refined, aiming at a dimensionless wall distance $(y+)$ between 1 and 5 . This was accomplished with the "inflation" feature available in ANSYS [41]. Depending on the variant, the near-wall element of the ceiling surface was divided into 12 to 15 layers (see Figure 9). Depending on the variant and its flow conditions, the elements on the water surface and around the pool borders were subdivided into 3 to 8 layers. The simulation results showed that, on these surfaces $y+<5$, was almost always achieved. Furthermore, the selected turbulence model includes a so-called "enhanced wall treatment" [42], so that the boundary layers with $y+>11$ are not resolved, but calculated with empirical wall functions. To simplify the mesh, certain surfaces were deliberately discretized, roughly aiming at a $y+>30$, e.g., the front and back surfaces (inner and exterior wall) for variants where no pronounced flow was expected along these surfaces. This was not the case for the variants with supply air along the exterior wall (A5, A6, B5 and B6).

In variants in which two sections (i.e., strand 2 and 3) were modeled, this resulted in about 2,500,000 elements.

Table 2. A summary of the resulting air exchange efficiency $(A C E)$ and contaminant removal efficiency $(C R E)$, as well as the mean velocity $v_{a v g}$ near the water surface $(10 \mathrm{~cm}$ above floor/water level). The following abbreviations are used: supply air (SA), extract air (EA), outer wall (OW) and inner wall (IW).

\begin{tabular}{|c|c|c|c|c|c|c|}
\hline ID & Variant Description & $\begin{array}{c}\text { Simulated } \\
\text { Flow }{ }^{*} \dot{V}_{S A} \\
{\left[\mathrm{~m}^{3} / \mathrm{h}\right]}\end{array}$ & $\begin{array}{c}A C E \\
\text { Total Vol. } \\
{[-]}\end{array}$ & $\begin{array}{c}\text { CRE Total } \\
\text { Volume } \\
{[-]}\end{array}$ & $\begin{array}{c}C R E \\
\text { Water Surf. } \\
{[-]}\end{array}$ & $\begin{array}{c}v_{a v g} \text { Water Surf. } \\
{[\mathrm{m} / \mathrm{s}]}\end{array}$ \\
\hline \multicolumn{7}{|c|}{ As-Is variants } \\
\hline A & High flow rate, $\beta=28 \mathrm{~m} / \mathrm{h}$ & $43,550(-4 \%)$ & 0.37 & 0.75 & 0.58 & 0.21 \\
\hline B & Low flow rate, $\beta=10 \mathrm{~m} / \mathrm{h}$ & $6850(-9 \%)$ & 0.39 & 0.79 & 0.69 & 0.13 \\
\hline \multicolumn{7}{|c|}{ Alternative variant } \\
\hline B1 & Vertically discharging & $7440(-2 \%)$ & 0.45 & 0.92 & 0.75 & 0.09 \\
\hline B2 & EA@OW & $6830(-10 \%)$ & 0.5 & 1.00 & 0.81 & 0.08 \\
\hline B3 & EA@OW + vert. discharging & $7430(-2 \%)$ & 0.45 & 0.97 & 0.77 & 0.11 \\
\hline B4 & EA@ pool edge & $6920(-8 \%)$ & 0.49 & 0.98 & 0.81 & 0.11 \\
\hline B7 & EA@ pool edge + vert. dis. & $7410(-2 \%)$ & 0.48 & 0.96 & 0.78 & 0.10 \\
\hline B5 & SA @ OW + EA @ IW (linear) & $7560(0 \%)$ & 0.48 & 0.98 & 0.84 & 0.19 \\
\hline B6 & SA @OW + EA @ IW $(1 \times)$ & $7560(0 \%)$ & 0.47 & 0.98 & 0.84 & 0.20 \\
\hline A5 & SA @ OW + EA @ IW (linear) & $50,400(0 \%)$ & 0.49 & 0.92 & 0.71 & 0.40 \\
\hline A6 & SA@OW + EA @ IW $(1 \times)$ & $50,400(0 \%)$ & 0.49 & 0.92 & 0.71 & 0.40 \\
\hline
\end{tabular}

${ }^{*}$ Due to the interpolation of the velocity profiles from a finer (diffuser model) to a coarser mesh (swimming hall model), the simulated supply air flow entering the hall model through the swirl diffuser hemisphere differed from the values specified in Table 2 . The relative difference is provided in brackets. The total mass balance of each model was always satisfied within $0.2 \%$.

\subsubsection{Physical Model}

Since the air flow in the hall is driven by the mechanical ventilation and by buoyancy currents due to density differences, the model should be able to simulate natural and forced convection. A characteristic length of $8 \mathrm{~m}$ and a temperature difference of $10 \mathrm{~K}$ results in a Rayleigh number of $>10^{11}$, i.e., high Rayleigh-number flow [43]. Convergence problems are often reported for this flow regime, e.g., [44].

To investigate the transport of pollutants and moisture, the "Species Transport" module available in ANSYS Fluent was activated. The components dry air, water vapor and tracer gas (with the properties for dry air) were included in the model, adding two conservation equations. The solution 
gives the mass fractions of these three components in spatial resolution. The tracer mass fraction was used to determine the age of air and thus the air exchange efficiency $(A C E)$. For this purpose, a constant and homogeneous mass source was imprinted in the entire volume of space in the simulation domain, resulting in a stationary exhaust air concentration of about $1000 \mathrm{ppm}$ (mass fraction). The water vapor emission according to the defined boundary condition (see Table 1) was modelled as a homogenous mass source within a $10 \mathrm{~cm}$ tall volume directly above the water surface. As for the tracer, the water vapor content as calculated beforehand should be present in the exhaust air when in a steady state. These two values were used, amongst others, to check the correct mass balance during simulation. The incompressible ideal gas equation was chosen to calculate the density of the gas mixture comprised of dry air, water vapor and tracer. Note that the Boussinesq approach [43] is not compatible with species transport and was therefore not applied.

Since surface temperatures strongly affect natural convection, the radiation exchange between surfaces should also be modeled. Therefore, the so-called "surface-to-surface" (S2S) method was selected, as this is considered a resource-saving and feasible approach as long one does not need to calculate the radiation temperature for every point in the domain. The view factors for the given geometry are calculated in a pre-processing step by the CFD software.

As a turbulence model, the $k-\varepsilon$ Re-Normalisation Group (RNG) was chosen, as it is often identified as a good compromise between accuracy and speed for mixed-convection applications, e.g., [30,45]. The so-called "enhanced wall treatment" available in Fluent was activated [42]. It combines, depending on the discretization of the near-wall elements, empirical wall functions and a two-layer approach for calculating the flow near the wall. If sufficiently finely discretized, the two-layer approach (fully turbulent layer and viscosity-specific layer) is applied; if the discretization is insufficient, the "enhanced wall function" is used.

As noted above, the "left and right" simulation domain bounds were set as a periodic constraint to reduce computer resources (see Figure 6). It can be assumed that the effects of those side walls on the air flow distribution are negligible for the central part of the swimming pool. However, the results presented here might not be fully representative for ventilation strand 1 and 4 (see Figure 3).

\subsubsection{Solver Settings and Convergence Criteria}

Within this study, a number of different meshing refinements as well as solver settings were tested and compared for reference variant " $\mathrm{A}$ ". Convergence problems arose only after including gravitation or variable density in the model. In general, the following procedure produced convergent solutions:

In a first step, a steady state simulation with the "coupled solver" setting (Courant flow number $=20$ ) was performed until the residuals, and in particular the convergence monitors, showed no appreciable changes. The following values were monitored to judge convergence: temperature, mass flow and mass fractions at the outlets, as well as mean temperature, velocity and tracer mass fraction for the lower hall volume (between floor/water and a height of $2 \mathrm{~m}$ ). At this point, the default convergence criteria (residuals $<10^{-3}$ or $<10^{-6}$ for energy and mass fraction) were reached in only a few cases. Typically, 200 to 500 iterations were calculated with these settings.

In a second step, a transient simulation with a time step of $\Delta t=1 \mathrm{~s}$ was performed for a total of $300 \mathrm{~s}$ simulated time. The mean values of the last 3 minutes were used for the evaluation of the result. With the exception of the volume-averaged velocity in the lower hall volume, all chosen convergence monitors did not change their value in a significant amount during this period. However, the volume-averaged velocity may still have exhibited variations of up to $10 \%$.

\subsection{CFD Model of the Swirl Diffusers}

In order to model the air flow from a swirl diffuser, a very fine discretization in the sub-millimeter range is required. Since modelling six or even 12 of these diffusers in one complete model would have exceeded the available computer resources, the flow from the swirl diffusers was calculated 
separately. The resulting flow and turbulence fields were used as boundary conditions in the swimming pool model.

A geometry model of the swirl diffuser was downloaded from the manufacturer's webpage [35]. It was reconstructed and parameterized (lamella position) within the ANSYS software. Due to the rotational symmetry of the diffuser, only a $60^{\circ}$ section was modelled. Note that in the horizontal discharge setting, there are two blades in this section, while there is only one blade in the case of the vertical discharge setting (see Figure 10).

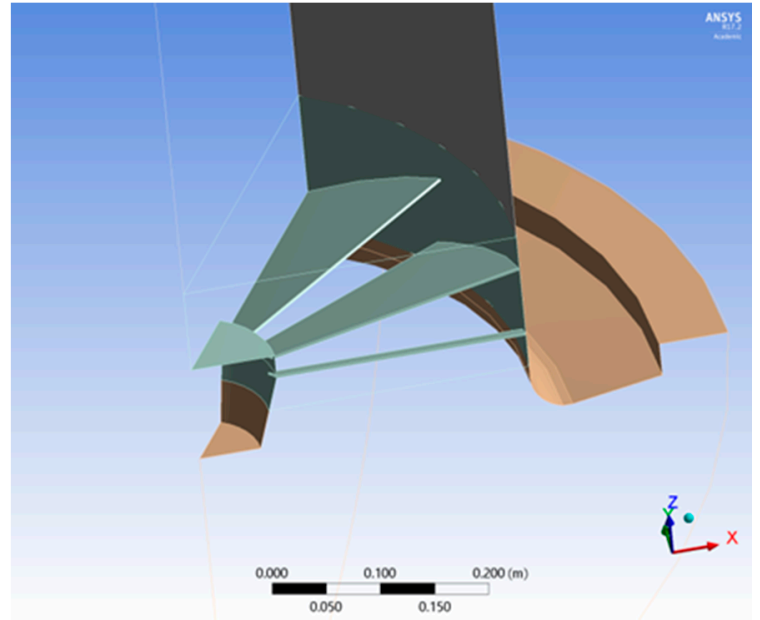

(a)

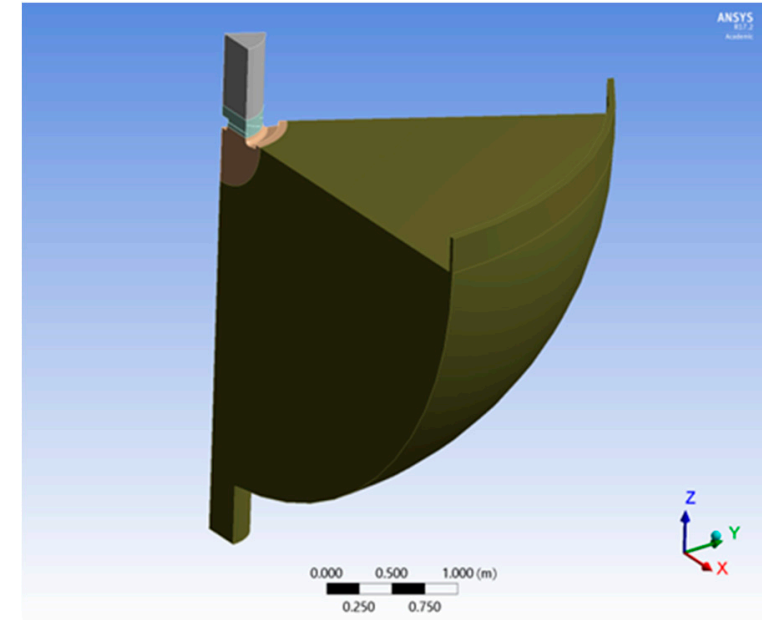

(b)

Figure 10. Three-dimensional model of the swirl diffuser: (a) "positive" model; (b) simulation domain composed of the swirl diffuser negative and a section of a-sphere with a $3 \mathrm{~m}$ radius. The velocity and turbulence conditions were measured at a radius of $0.5 \mathrm{~m}$. Note that, due to rotational symmetry, only a $60^{\circ}$ section was modelled.

A tetrahedral mesh was applied throughout the simulation domain. A default element size of 1-2 cm was selected for the various volume sections in and close to the diffuser. However, the element sizes were limited to $2 \mathrm{~mm}$ for the lamella surfaces and $5 \mathrm{~mm}$ for the diffuser surfaces at the outlet. Additionally, the wall elements were subdivided using the "inflation" function, resulting in sub-millimeter range elements (see Figure 11). The simulation domain was extended in the direction of discharge by a spherical volume with a radius of $3 \mathrm{~m}$. The elements in that volume were limited to $<5 \mathrm{~cm}$. These settings resulted in a mesh with approx. 2.3 million elements. As needed, this mesh was further refined within Fluent after the first round of iterations to limit the dimensionless wall distance $(y+)$ to $<3-5$. After the refinement, the number of elements increased depending on the model variant to up to 8 million. There was no notable difference when directly comparing the flow fields of the last refinement steps. A visualization of the resulting $y+$ of the final diffuser models is shown in Figure 12.

Besides comparing results at different mesh refinement stages, several test simulations with different solver settings and turbulence models were tested and compared. Very similar results were obtained with all tested turbulence models, i.e., $k-\omega$ shear stress transport (SST), $k-\varepsilon$ RNG with enhanced wall treatment and $k-\varepsilon$ RNG with standard wall function (see Figure 13). However, depending on the solver settings, obtaining convergence was not equally reliable or fast. Convergence was judged via residuals and certain flow field monitors. Finally, the following settings were chosen: $k-\varepsilon$ RNG with enhanced wall treatment, coupled solver and 2nd order upwind discretization scheme for $k, \varepsilon$, pressure and impulse.

Simulations were performed with a supply air temperature of $30^{\circ} \mathrm{C}$ and $40^{\circ} \mathrm{C}$ and with the lamella position corresponding to horizontal and vertical discharge mode, resulting in four different sets of solutions. For the simulations with a supply air temperature of $40^{\circ} \mathrm{C}$ (winter case), the temperature in 
the room volume was maintained at around $30^{\circ} \mathrm{C}$ by applying a homogenous heat sink. The change in supply air temperature did not notably influence the results.

The velocity and turbulence fields $(k$ and $\varepsilon$ ) on a sphere with a radius of $0.5 \mathrm{~m}$ around the center of the diffuser outlet were exported. After applying certain post-processing steps, these profiles were imported as a boundary condition within the pool hall model.

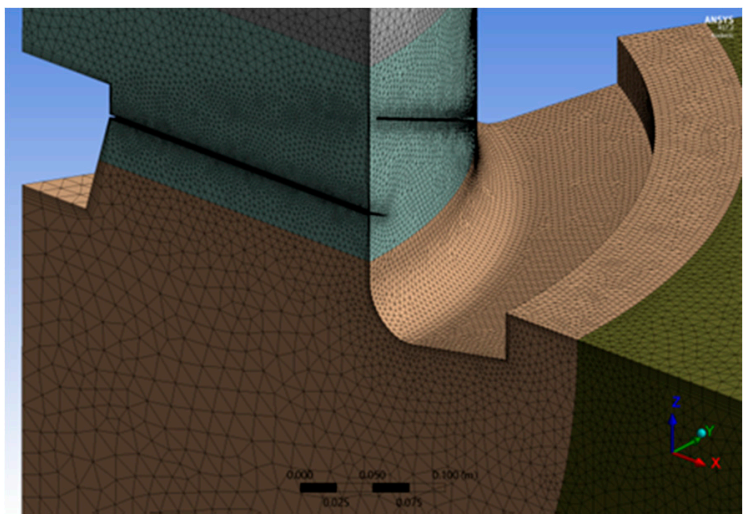

(a)

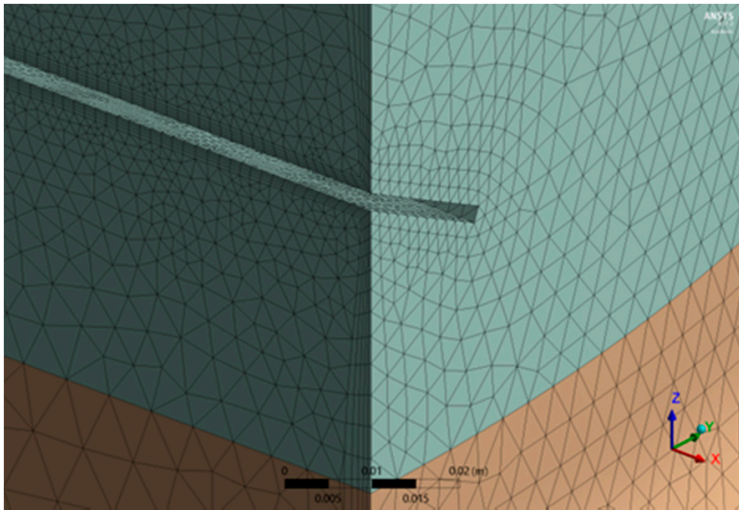

(b)

Figure 11. Three-dimensional views of the swirl diffuser model with tetrahedral mesh: (a) view of diffuser outlet; (b) view of lamella region. Note that the element size of $2 \mathrm{~mm}$ was further reduced using the so-called inflation function, resulting in a sub-millimeter cell thickness at those critical surfaces.

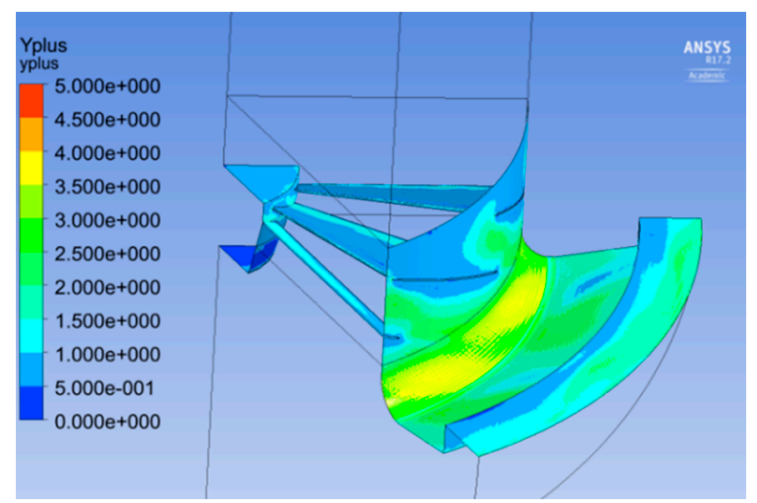

(a)

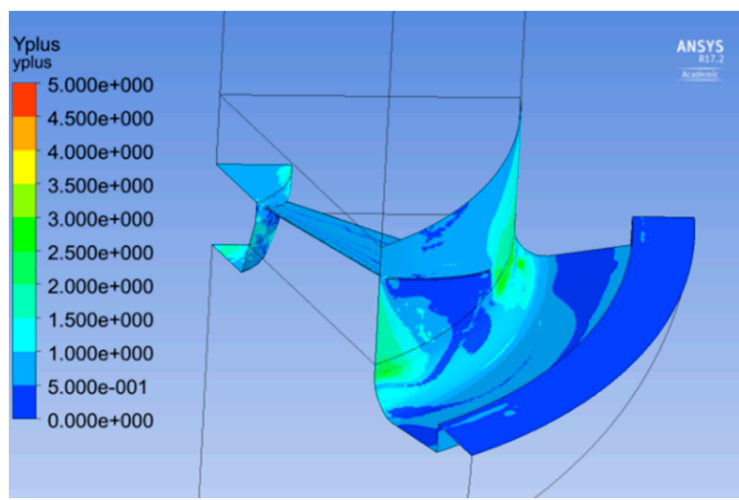

(b)

Figure 12. Contour plot of the resulting dimensionless wall distance $y+$ of relevant surfaces of the swirl diffuser with (a) horizontal discharging; (b) vertical discharging setting.

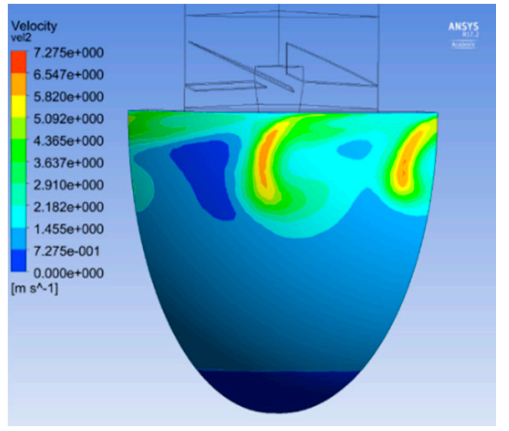

(a)

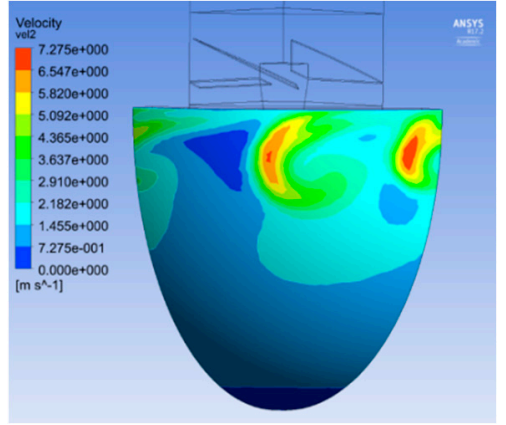

(b)

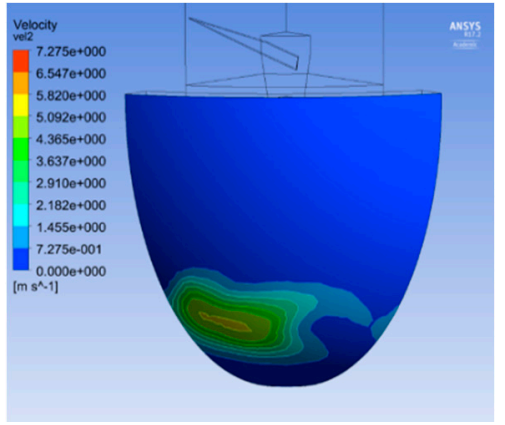

(c)

Figure 13. Contour plot of the velocity field at the surface with radius $0.5 \mathrm{~m}$ : (a) horizontal discharging calculated with the turbulence model $k-\omega$ shear stress transport (SST); (b) horizontal discharging with $k$ - $\varepsilon$ Re-Normalisation Group (RNG); (c) vertical discharging with $k-\varepsilon$ RNG. 


\subsection{Evaluation metrics}

To assess ventilation efficiency, a number of different metrics are available. Their advantages and disadvantages have been studied and documented in a number of publications: e.g., [46-49]. For the evaluation of the herein presented CFD-simulations, the following two metrics were used as they seemed most suitable:

Air Exchange Efficiency $(A C E)$ : This indicates how effectively the supply air is used to flush the entire room volume and is defined as follows:

$$
A C E=\frac{\tau_{\text {nom }}}{2\left\langle\tau_{\text {lokal }}\right\rangle}
$$

where $\tau_{\text {nom }}$ is the nominal age of air and the inverse of the air exchange rate; i.e., it indicates how long it takes in an ideal case to exchange the air in the entire volume of space. $\left\langle\tau_{\text {lokal }}\right\rangle$ is the spatial average of the local age of air. In the presented simulations, it is determined using a homogeneous tracer source. The definition of the $A C E$ is such that it become 1 for a pure piston flow and 0.5 in a perfectly mixed condition. $A C E<0.5$ indicates a short circuit flow.

Contaminant Removal Efficiency (CRE): This indicates how effectively a substance is removed from the room and is defined as follows:

$$
C R E=\frac{c_{\text {outlet }}-c_{\text {inlet }}}{\langle c\rangle-c_{\text {inlet }}}
$$

where $c_{\text {outlet }}$ and $c_{\text {inlet }}$ are the pollutant concentration at the extract air outlet and the supply air inlet, respectively. $\langle c\rangle$ is the spatially averaged concentration in the relevant area. In principle, values from zero to infinity are possible. Perfect mixing results in a value of 1 . However, CRE strongly depends on the position of the pollutant source and the considered volume of space; e.g., $C R E$ would result in an infinite value if the pollutant source were positioned directly at the extract air outlet. The $C R E$ was evaluated for different areas. Table 2 gives the CRE for the total volume, and more importantly, for the area relevant to swimmers. A plane $10 \mathrm{~cm}$ above the water surface was therefore chosen. Since this plane spatially coincides with the pollutant source volume, $C R E>1$ is not possible.

The values of $A C E$ and $C R E$ were calculated using the software "Post" available within the ANSYS software package.

\section{Results and Discussion}

The results for $A C E$ and $C R E$ for the simulated as-is and alternative variants are summarized in Table 2.

With $A C E$ values of 0.37 and 0.39 , the as-is variants have the lowest ventilation efficiency of all variants. This enforces the concern that a short circuit flow is present in this ventilation configuration of the swimming pool hall. The average age of air is $2.96 \mathrm{~h}$ compared to $2.34 \mathrm{~h}$ for perfect mixing. In a perfectly mixed situation $(A C E=0.5)$, variant " $\mathrm{B}$ " would have an average absolute humidity of $16 \mathrm{~g} / \mathrm{kg}$, but the simulation results show values mostly between 18 and $21 \mathrm{~g} / \mathrm{kg}$ (see Figure 14). The simulated room average is $20.1 \mathrm{~g} / \mathrm{kg}$. Assuming constant water evaporation rates, a ventilation concept with an $A C E$ of 0.5 could maintain this value with a supply air flow of approx. $5200 \mathrm{~m}^{3} / \mathrm{h}$ instead of $6850 \mathrm{~m}^{3} / \mathrm{h}$, equivalent to a $25 \%$ reduction. This comparison illustrates the optimization potential for the existing ventilation configuration.

Note that for variant "B", the humidity content with perfect mixing should be $16 \mathrm{~g} / \mathrm{kg}$ instead of $15 \mathrm{~g} / \mathrm{kg}$ as specified in Table 1 . This is due to variations in the simulated supply air flow (see Table 2). It can be safely assumed that $A C E$ and $C R E$ are not affected significantly by slight variations in supply air flow. However, when comparing concentration values, the difference in air exchange rate needs to be considered. All simulation results satisfied a total mass balance within $<0.2 \%$. 


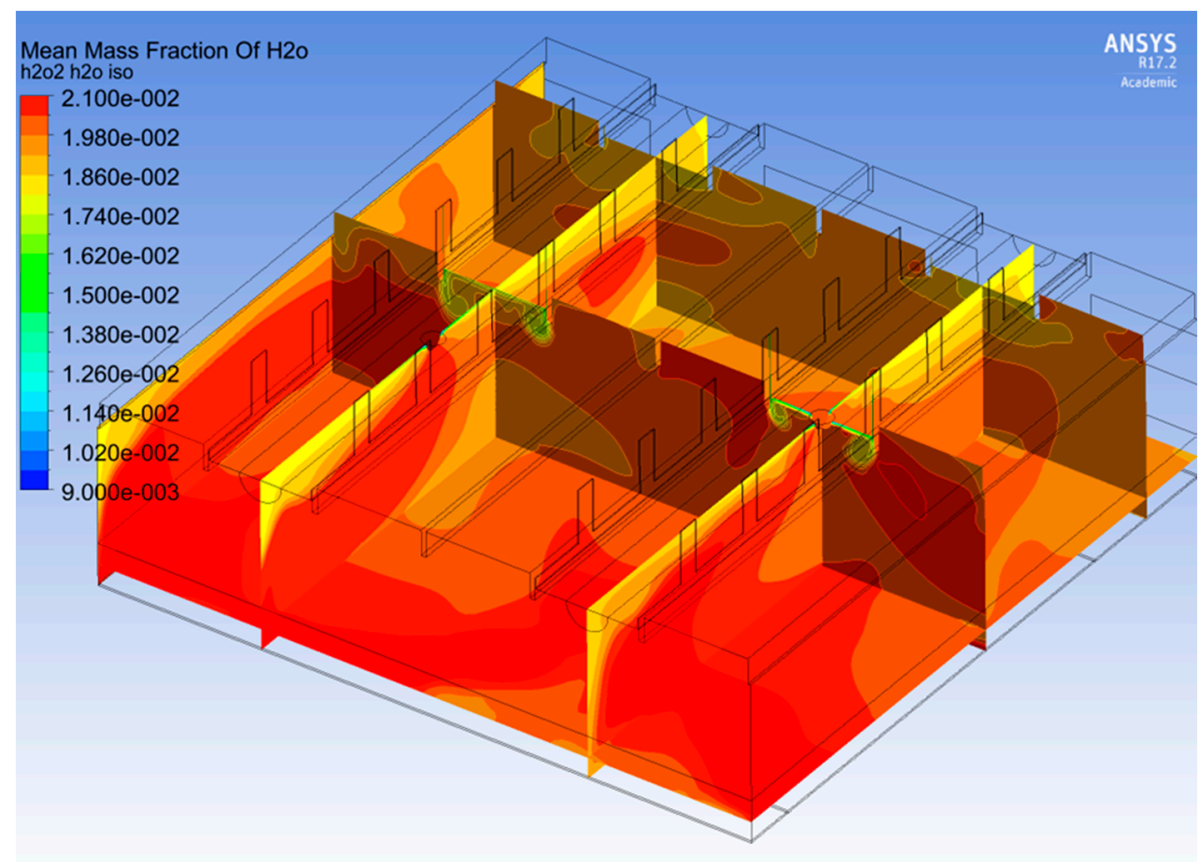

Figure 14. Absolute humidity distribution in various sectional planes in the hall in variant " $B$ ". Perfect mixing would result in a spatial average of $0.016 \mathrm{~kg} / \mathrm{kg}$.

These results seem plausible when compared to the (limited) available measured data. At two sensor locations, the absolute humidity during a week in winter ranges roughly between 17 and $20 \mathrm{~g} / \mathrm{kg}$; at a third location, it ranges between 14 and $16 \mathrm{~g} / \mathrm{kg}$ (see Figure 5). The measured mean total supply air flow provided by both ventilation units in this period ranges between 9500 and $10,000 \mathrm{~m}^{3} / \mathrm{h}$, i.e., roughly between 7500 and $8000 \mathrm{~m}^{3} / \mathrm{h}$ into the swimming pool hall (assuming that $20 \%$ is supplied into the water slide area).

When considering the removal of pollutants above the water surface (outgassing disinfection by-products), the as-is variant can be considered ineffective. According to the CFD simulations, the CRE with respect to the water surface is 0.58 and 0.69 for as-is variant " $\mathrm{A}$ " (high flow rate) and $\mathrm{B}$ (low flow rate), respectively. Note that the CRE can maximally reach a value of 1 .

A clear improvement can be achieved if the swirl diffusers are set to discharge vertically instead of horizontally (see variant "B1"). The $A C E$ raises to 0.45 and the $C R E$ at the water surface to 0.75 . The resulting absolute humidity is around $16 \mathrm{~g} / \mathrm{kg}$. This finding generally agrees well with [24], where simulation results also indicate that directing the supply air jets further down, i.e., into the occupied area, reduces and homogenized the age of air significantly.

In variant "B2", the extract air outlets were positioned on the exterior wall near the floor, improving ventilation efficiency further. The extract air openings were modelled in the panels which cover the ventilation ducts in the outer wall (see Figure 3), and the original extract air openings (shadow gap) were disabled. This results in an ACE corresponding to a perfectly mixed condition, and the CRE at the water surface is 0.81 , while relatively low air velocities are present near the water surface (see Table 2). The resulting absolute humidity distribution is shown in Figure 15. Improved indoor air quality for a ventilation concept with extraction points near the bottom of the hall was also observed during measurements of THMs in various swimming pools [12] and is also reported by a HVAC planner specialized in swimming pools [37].

Using vertically discharging swirl outlets in combination with this extract air outlet configuration (variant "B3") reduced ACE and CRE slightly compared to variant "B2".

Extracting the air along the edges of the pool, e.g., in the pool overflow channels (variant "B4"), resulted in similar ventilation efficiencies as variant "B2". Based on simpler 2D CFD simulations, 
performed during a preliminary study, a higher ventilation efficiency was expected for this configuration [38]. Nevertheless, the pollutant discharge efficiency reaches the second highest value (0.81) in comparison with all variants simulated herein, while exhibiting relatively low air velocities along the water surface.

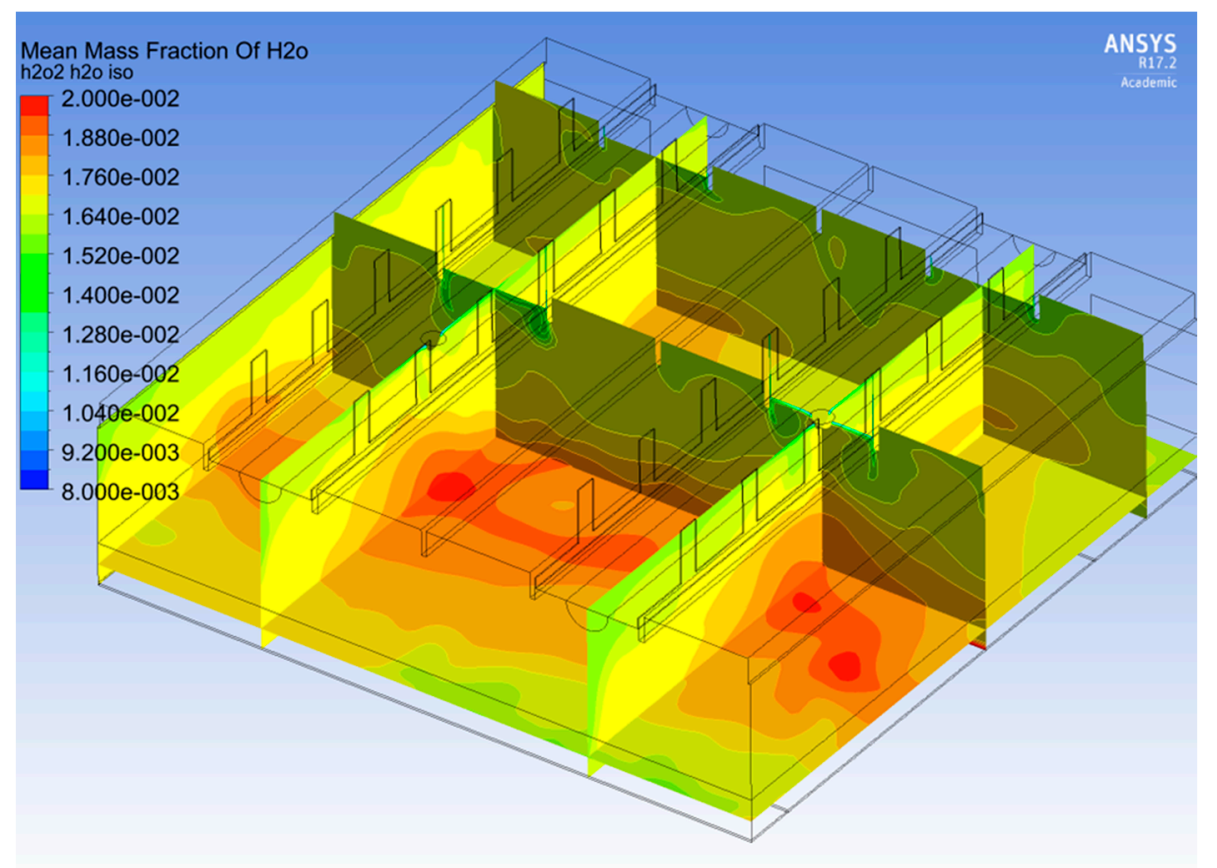

Figure 15. Absolute humidity distribution in various sectional planes with a vertically discharging swirl diffuser (variant “B2"). Perfect mixing would result in a spatial average of around $0.016 \mathrm{~kg} / \mathrm{kg}$.

The variants with the highest $C R E$ in relation to the water surface are those with the supply of air along the exterior wall and the extraction along the inner wall. Here, two different variants were modelled. In "B5", the extract outlets were distributed along the entire inner wall side near the floor. In "B6", only one extract air outlet was positioned within the simulation domain (one of four ventilation strands). The opening was placed near the floor and near the edge of the simulation domain having a mirror symmetry condition. Variant "B6" therefore corresponds to a situation with only two extract air outlets for the entire hall. Both variants result in an ACE of 0.47 and 0.48 , i.e., values corresponding to almost perfect mixing, and CREs of 0.84 . Figure 16 shows that areas with higher humidity and pollutant concentrations (with equivalent distributions) are mostly limited to just above the source (water surface). For comparison, Figure 17 shows the concentration distribution of variant "B1". However, according to the simulation results, significantly higher air velocities near the water surface and around the pool can be expected compared to the variants with air supply from the ceiling (see Table 2).

It should be noted here that these simulation results do not account for air movements produced by persons moving in and around the pool, e.g., walking adults or jumping children at play. Such movements would increase mixing in the lower volume of the hall. Since the air exchange efficiency of all simulations is always $\leq 0.5$, it can be assumed that modelling such air movements would improve simulated ventilation efficiency, as observed in [27]. Therefore, these simulation results of air exchange efficiency can be considered the worst case, representing times of low pool activity.

Additionally, two variants at a nominal flow rate $\left(50,400 \mathrm{~m}^{3} / \mathrm{h}\right.$ ) were simulated (see Table 2 ("A5" and "A6")). As with the as-is configuration, the CRE decreases at higher volume flows, but it can be assumed that the absolute pollutant concentration is about the same as (assuming that the pollutant emission correlates with the water evaporation) or lower than (assuming that the pollutant emission is 
more likely constant) in the low-flow condition. However, high air velocities near the water and floor could result in uncomfortable drafts.

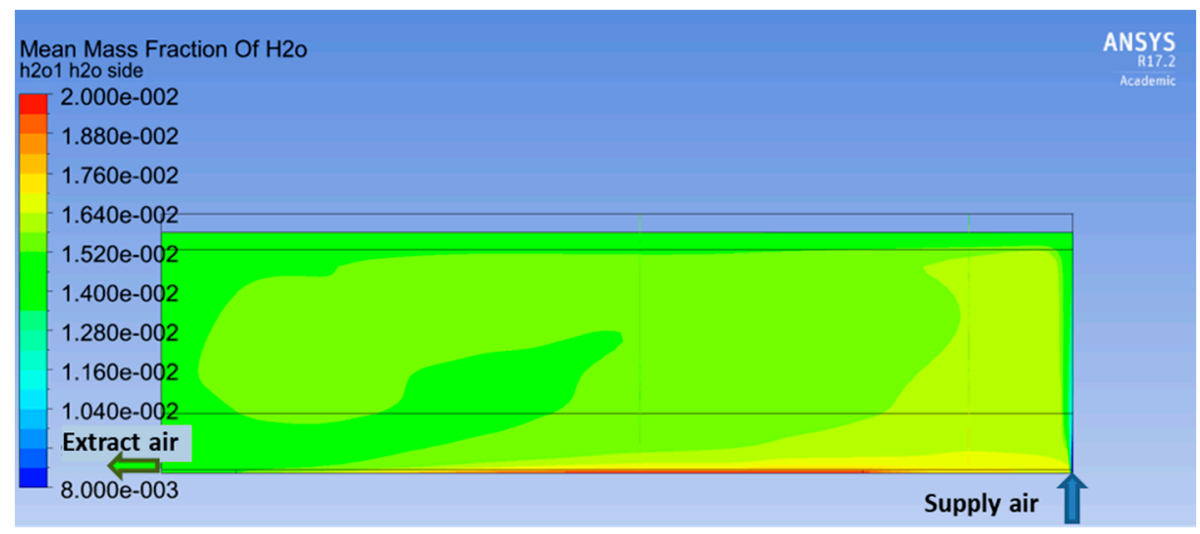

Figure 16. Absolute humidity distribution in center plane of ventilation strand 3 (see Figure 3) for variant "B5" with supply air introduced upward along the outer wall and extract air being extracted along the inner wall.

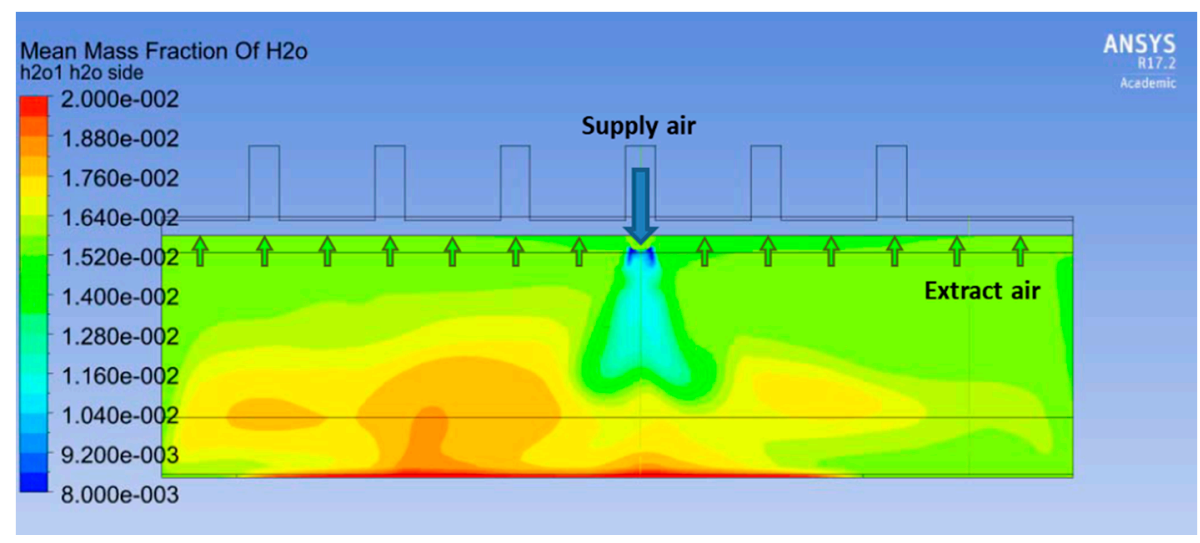

Figure 17. Absolute humidity distribution in center plane of ventilation strand 3 (see Figure 3) for variant "B1" (vertically discharging swirl diffuser).

\section{Conclusions}

This study investigated possible ventilation approaches for a particular highly energy efficient swimming pool hall. Due to the high thermal quality of the building envelope, the air exchange rates compared to conventional swimming pools can be reduced and recirculation air avoided without the risk of condensation on or in the building structure. Therefore, it is crucial to supply fresh air and remove air contaminants-in particular, disinfection by-products-as effectively as possible. The results of the presented CFD simulations indicate that the ventilation efficiency in the examined swimming pool could be improved with alternative air distribution concepts identified to provide better ventilation efficiency. A simple improvement could be to change the swirl diffusers from horizontally discharging to vertically discharging.

Higher air exchange efficiency $(A C E)$ and contaminant removal efficiency $(C R E)$ were obtained when the extract air openings were positioned near the ground. This result agrees with observations reported in [12,37]. The exact arrangement of the extract air openings (linear vs. punctual extraction) does not seems to be of great importance. An upwardly directed supply air outlet along the outer (possibly also inner) wall could allow for additional improvement over supply via swirl outlets (vertical or horizontal discharging).

The results of this simulation study should be interpreted with care. The CFD simulations were performed assuming steady-state boundary conditions, and only two volume flow conditions 
representing a winter and a summer scenario were considered. In real conditions, change throughout the operation and ventilation flow is constantly adapted. Additionally, the movements of pool users and personnel in and around the pool could notably change air movement patterns, in particular in the lower hall volume. However, the simulated boundary conditions can be considered representative, and movement by people would increase mixing and therefore air exchange efficiency, since all results were $\leq 0.5$. A clear limitation is also the fact that the simulated results have not been thoroughly validated experimentally.

Nevertheless, other studies have shown that, in general, CFD simulation and in particular the chosen turbulence model is capable of reproducing air flow patterns in swimming pools or other large spaces buildings with satisfactory results $[27,29,30]$. This work documents a CFD methodology to assess ventilation in large swimming pool halls while considering small-scale diffuser geometry with low computational resources.

Potential solutions for improving ventilation efficiency were presented for the investigated swimming pool hall. Their actual performance should be verified experimentally and other swimming pool halls should be investigated before deriving generalized recommendations. Therefore, further research efforts are planned to validate these CFD results and to perform more simulations based on the presented methodology.

Author Contributions: Conceptualization, G.R. and J.G.S.; Methodology, G.R.; Software, G.R.; Formal Analysis, G.R.; Writing-Original Draft Preparation, G.R. and J.G.S.; Visualization, G.R. and J.G.S.; Funding Acquisition, J.G.S.

Funding: This research was funded by the German Federal Environmental Foundation (DBU), grant number 33217/01-24/2.

Acknowledgments: We cordially want to thank Christoph Speer for helpful advices with CFD modelling.

Conflicts of Interest: The authors declare no conflict of interest. The funders had no role in the design of the study; in the collection, analyses, or interpretation of data; in the writing of the manuscript; and in the decision to publish the results.

\section{References}

1. Westerlund, L.; Dahl, J.; Johansson, L. A theoretical investigation of the heat demand for public baths. Energy 1996, 21, 731-737. [CrossRef]

2. Schulz, T.; Pfluger, R.; Grove-Smith, J.; Kah, O.; Krick, B. Grundlagenuntersuchung der Bauphysikalischen und Technischen Bedingungen zur Umsetzung des Passivhauskonzepts im Öffentlichen Hallenbad; Bädergesellschaft Lünen mbH: Darmstadt, Germany, 2009.

3. Zuccari, F.; Santiangeli, A.; Orecchini, F. Energy analysis of swimming pools for sports activities: Cost effective solutions for efficiency improvement. Energy Procedia 2017, 126, 123-130. [CrossRef]

4. Kampel, W.; Aas, B.; Bruland, A. Energy-use in Norwegian swimming halls. Energy Build. 2013, 59, 181-186. [CrossRef]

5. CIBSE. Energy Efficiency in Swimming Pools_For Centre Managers and Operators; CIBSE: London, UK, 1997; pp. 1-7.

6. Sun, P.; Wu, J.Y.; Wang, R.Z.; Xu, Y.X. Analysis of indoor environmental conditions and heat pump energy supply systems in indoor swimming pools. Energy Build. 2011, 43, 1071-1080. [CrossRef]

7. Ribeiro, E.M.A.; Jorge, H.M.M.; Quintela, D.A.A. An approach to optimised control of HVAC systems in indoor swimming pools. Int. J. Sustain. Energy 2016, 35, 378-395. [CrossRef]

8. Johansson, L.; Westerlund, L. Energy savings in indoor swimming-pools: Comparisons betweendifferent heat-recovery systems. Appl. Energy 2001, 70, 281-303. [CrossRef]

9. Gollowitzer, E.; Gressier, F.; Peper, S. Passivhaus-Hallenbad Bambados Monitoring; Passivhaus Institut: Darmstadt, Germany, 2015.

10. Peper, S.; Grove-Smith, J. Monitoring Passivhaus-Hallenbad Lippe-Bad Lünen; Passivhaus Institut: Darmstadt, Germany, 2013. 
11. Ahrens, O.; Beckert, S.; Franke, T.; Grove-Smith, J.; Hitz, A.; Horstmann, W.; Kah, O.; Koch, G.; Krick, B.; Ostermann, U.; et al. Integrale Planung für die Realisierung eines öffentlichen Hallenbades mit Konzepten der Passivhaustechnologie; Passivhaus Institut: Darmstadt, Germany, 2011.

12. Gollowitzer, E.; Grove-Smith, J.; Peper, S. Passivhaus-Konzept für Hallenbäder: Datenauswertung und Empfehlungen; Passivhaus Institut: Darmstadt, Germany, 2018.

13. Grove-Smith, J.; Aydin, V.; Feist, W.; Schnieders, J.; Thomas, S. Standards and policies for very high energy efficiency in the urban building sector towards reaching the $1.5 \mathrm{C}$ target. Environ. Sustain. 2018, 103-114. [CrossRef]

14. Passive House Institute Criteria for the Passive House. EnerPHit and PHI Low Energy Building Standard; Passive House Institute Criteria for the Passive House: Darmstadt, Germany, 2016; pp. 1-27.

15. Schnieders, J.; Feist, W.; Rongen, L. Passive Houses for different climate zones. Energy Build. 2015, 105, 71-87. [CrossRef]

16. Gollowitzer, E.; Grove-Smith, J.; Peper, S.; Schulz, T. Passivhaus-Konzept für Hallenbäder: Leitfaden; Passivhaus Institut: Darmstadt, Germany, 2018.

17. Zwiener, C.; Richardson, S.D.; De Marini, D.M.; Grummt, T.; Glauner, T.; Frimmel, F.H. Drowning in disinfection byproducts? Assessing swimming pool water. Environ. Sci. Technol. 2007, 41, 363-372. [CrossRef] [PubMed]

18. Chowdhury, S.; Al-hooshani, K.; Karanfil, T. Disinfection byproducts in swimming pool: Occurrences, implications and future needs. Water Res. 2014, 53, 68-109. [CrossRef] [PubMed]

19. Weng, S.C.; Weaver, W.A.; Zare Afifi, M.; Blatchley, T.N.; Cramer, J.S.; Chen, J.; Blatchley, I.R. Dynamics of gas-phase trichloramine $\left(\mathrm{NCl}_{3}\right)$ in chlorinated, indoor swimming pool facilities. Indoor Air 2011, 21, 391-399. [CrossRef] [PubMed]

20. Bowen, A.B.; Kile, J.C.; Otto, C.; Kazerouni, N.; Austin, C.; Blount, B.C.; Wong, H.N.; Beach, M.J.; Fry, A.M. Outbreaks of short-incubation ocular and respiratory illness following exposure to indoor swimming pools. Environ. Health Perspect. 2007, 115, 267-271. [CrossRef] [PubMed]

21. Bougalt, V.; Turmel, J.; Boulet, L.; Levesque, B. The Respiratory Health of Swimmers. Sport. Med. 2009, 39, 295-312. [CrossRef] [PubMed]

22. Weisel, C.P.; Richardson, S.D.; Nemery, B.; Aggazzotti, G.; Baraldi, E.; Blatchley, E.R.; Blount, B.C.; Carlsen, K.H.; Eggleston, P.A.; Frimmel, F.H.; et al. Childhood asthma and environmental exposures at swimming pools: State of the science and research recommendations. Environ. Health Perspect. 2009, 117, 500-507. [CrossRef] [PubMed]

23. Chu, T.-S.; Cheng, S.-F.; Wang, G.-S.; Tsai, S.-W. Occupational exposures of airborne trichloramine at indoor swimming pools in Taipei. Sci. Total Environ. 2013, 461-462, 317-322. [CrossRef] [PubMed]

24. Limane, A.; Fellouah, H.; Galanis, N. Three-dimensional OpenFOAM simulation to evaluate the thermal comfort of occupants, indoor air quality and heat losses inside an indoor swimming pool. Energy Build. 2018, 167, 49-68. [CrossRef]

25. Koper, P.; Lipska, B.; Michnol, W. Assessment of Thermal Comfort in an Indoor Swimming-Pool Making Use of the Numerical Prediction CFD. Archit. Civ. Eng. Environ. 2010, 3, 95-104.

26. Palmowska, A.; Lipska, B. Research on improving thermal and humidity conditions in a ventilated ice rink arena using a validated CFD model. Int. J. Refrig. 2018, 86, 373-387. [CrossRef]

27. Limane, A.; Fellouah, H.; Galanis, N. Simulation of airflow with heat and mass transfer in an indoor swimming pool by OpenFOAM. Int. J. Heat Mass Transf. 2017, 109, 862-878. [CrossRef]

28. Palmowska, A.; Lipska, B. Experimental study and numerical prediction of thermal and humidity conditions in the ventilated ice rink arena. Build. Environ. 2016, 108, 171-182. [CrossRef]

29. Ciuman, P.; Lipska, B. Experimental validation of the numerical model of air, heat and moisture flow in an indoor swimming pool. Build. Environ. 2018, 145, 1-13. [CrossRef]

30. Wang, H.; Tang, X.; Huang, C.; Wang, H.; Tang, X.; Huang, C. Investigating ventilation system performance in large space building: A nozzle primary air supply with secondary airflow-relay system. Sci. Technol. Built Environ. 2017, 23, 296-306. [CrossRef]

31. Blázquez, J.L.F.; Maestre, I.R.; Gallero, F.J.G.; Gómez, P.Á. A new practical CFD-based methodology to calculate the evaporation rate in indoor swimming pools. Energy Build. 2017, 149, 133-141. [CrossRef]

32. Li, Z.; Heiselberg, P.K. CFD Simulations for Water Evaporation and Airflow Movement in Swimming Baths; Instituttet Bygningsteknik Aalborg Univ.: Aalborg, Denmark, 2005. 
33. Srebric, J.; Chen, Q. Simplified Numerical Models for Complex Air Supply Diffusers. HVACER Res. 2002, 8, 277-294.

34. Li, Y.; Nielsen, P.V. Commemorating 20 years of Indoor Air: CFD and ventilation research. Indoor Air 2011, 21, 442-453. [CrossRef] [PubMed]

35. Trox Swirl Diffusers-Type VDL. Available online: https://www.trox.at/en/swirl-diffusers/type-vdla047654375f246da (accessed on 10 September 2018).

36. VDI. Richtlinie VDI 2089—Blatt 1: Technische Gebäudeausrüstung von Schwimmbädern; VDI: Frankfurt am Main, Germany, 2010.

37. Kaluza, J. Aktuelle Versuche: Luftführung abwärts! In Dr. Jentsch Schwimmbadseminare "Energieeffizienz"; Dr. Nüsken Chemie GmbH: Nuernberg, Germany, 2016.

38. Rojas, G. Sanierung Telfer Bad: CFD-Simulationen zu möglichen Luftführungskonzepten; Internal report, Unit for Energy Efficient Buildings, University of Innsbruck: Innsbruck, Austria, 2013.

39. www.CFD-Online.com Incompressible Flow. Available online: https://www.cfd-online.com/Wiki/ Incompressible_flow (accessed on 7 November 2018).

40. Fluent Inc. ANSYS Fluent 14.0 UDF Manual; Fluent Inc.: New York, NY, USA, 2011.

41. ANSYS ANSYS Mesh Inflation Group. Available online: https://www.sharcnet.ca/Software/Ansys/17.0/ en-us/help/wb_msh/ds_Inflation_Group.html (accessed on 12 September 2018).

42. ANSYS ANSYS Fluent—Enhanced Wall Treatment. Available online: http://aerojet.engr.ucdavis.edu/ fluenthelp/html/ug/node514.htm (accessed on 2 February 2015).

43. ANSYS Natural Convection and Buoyancy-Driven Flows. Available online: https://www.sharcnet.ca/ Software/Ansys/16.2.3/en-us/help/flu_ug/flu_ug_sec_hxfer_buoy.html (accessed on 16 September 2018).

44. Convergenc Problems: High Rayleigh Number Flows. Available online: https://www.cfd-online.com/ Forums / fluent/102996-questions-about-high-rayleigh-number-natural-convection-heat-transfer.html (accessed on 15 September 2018).

45. Zhang, Z.; Zhang, W.; Zhai, Z.; Chen, Q. Evaluation of various turbulence models in predicting airflow and turbulence in enclosed environments by CFD: Part 2-Comparison with experimental data from. HvacER Res. 2007, 13, 871-887.

46. Etheridge, D.; Sandberg, M. Definition of air-exchange efficiency. In Building Ventilation-Theory and Measurement; John Wiley \& Sons: Hoboken, NJ, USA, 1996; p. 267.

47. Novoselac, A. Comparison of Air Exchange Efficiency and Contaminant Removal Effectiveness as IAQ Indices. ASHRA 2003, 109, 1-11.

48. Lim, E.; Ito, K.; Sandberg, M. New ventilation index for evaluating imperfect mixing conditions-Analysis of Net Escape Velocity based on RANS approach. Build. Environ. 2013, 61, 45-56. [CrossRef]

49. Sandberg, M. What is ventilation efficiency? Build. Environ. 1981, 16, 123-135. [CrossRef] 